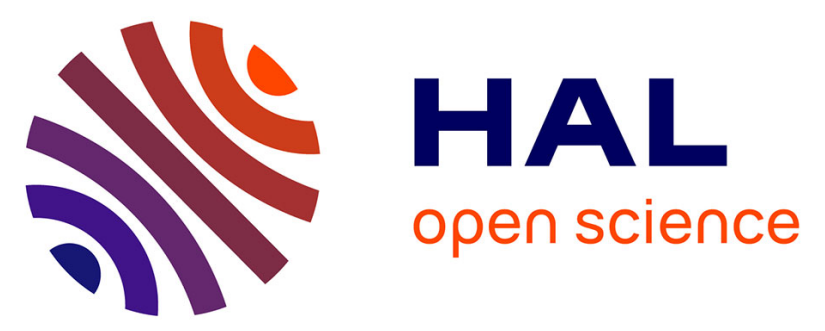

\title{
Cationic Thermoresponsive Poly( N -vinylcaprolactam) Microgels Synthesized by Emulsion Polymerization Using a Reactive Cationic Macro-RAFT Agent
}

Laura Etchenausia, Elise Deniau-Lejeune, Annie Brûlet, Jacqueline Forcada, Maud Save

\section{To cite this version:}

Laura Etchenausia, Elise Deniau-Lejeune, Annie Brûlet, Jacqueline Forcada, Maud Save. Cationic Thermoresponsive Poly( N -vinylcaprolactam) Microgels Synthesized by Emulsion Polymerization Using a Reactive Cationic Macro-RAFT Agent. Macromolecules, 2018, 51 (7), pp.2551 - 2563. 10.1021/acs.macromol.8b00155 . hal-01781636

\section{HAL Id: hal-01781636 \\ https://hal-univ-pau.archives-ouvertes.fr/hal-01781636}

Submitted on 2 Dec 2020

HAL is a multi-disciplinary open access archive for the deposit and dissemination of scientific research documents, whether they are published or not. The documents may come from teaching and research institutions in France or abroad, or from public or private research centers.
L'archive ouverte pluridisciplinaire HAL, est destinée au dépôt et à la diffusion de documents scientifiques de niveau recherche, publiés ou non, émanant des établissements d'enseignement et de recherche français ou étrangers, des laboratoires publics ou privés. 


\section{Cationic thermoresponsive poly $(N$-vinylcaprolactam $)$ microgels synthesized by emulsion polymerization using a reactive cationic macroRAFT agent.}

Laura Etchenausia, ${ }^{\dagger}, \stackrel{\dagger}{ }$ Elise Deniau, ${ }^{\dagger}$ Annie Brûlet, ${ }^{\#}$ Jacqueline Forcada, ${ }^{* \dagger}$ Maud Save,,,$\dagger$

$\uparrow$ CNRS, University Pau \& Pays Adour, Institut des Sciences Analytiques et de Physico-Chimie pour l'Environnement et les Matériaux, IPREM, UMR5254, 64000, PAU, France

† Departamento de Química Aplicada, Facultad de Ciencias Químicas, Universidad del País Vasco UPV/EHU, 20018 Donostia-San Sebastian, Spain.

\# CEA CNRS CEA Saclay, UMR12, Laboratoire Léon Brillouin, F-91191 Gif Sur Yvette, France

Corresponding authors: jacqueline.forcada@ehu.es, maud.save@univ-pau.fr

\section{ABSTRACT}

A series of reactive poly([2-(acryloyloxy)ethyl]trimethylammonium chloride) (P(AETAC)) cationic polymers with varying degrees of polymerization was synthesized by RAFT/MADIX polymerization and investigated as stabilizers for the emulsion polymerization of $\mathrm{N}$ vinylcaprolactam (PVCL) in the presence of a crosslinker. It was demonstrated that the xanthate chain-end of the cationic $\mathrm{P}(\mathrm{AETAC}-\mathrm{X})$ polymers played a crucial role to produce stable cationic PVCL-based microgels at higher initial solids content (5 - $10 \mathrm{wt}$-\%) than usually reported for the synthesis of PVCL microgels. The thermoresponsive PVCL microgels with cationic shell undergo a reversible volume shrinkage upon heating in the absence of any hysteresis in accordance with the narrow particle size distribution. The values of the volume 
phase transition temperature ranged between $28{ }^{\circ} \mathrm{C}$ and $30^{\circ} \mathrm{C}$ for the microgels synthesized using 4 and 8 wt- $\%$ of P(AETAC-X) based on VCL. The presence of a cationic outer shell onto the microgels was evidenced by the positive values of the electrophoretic mobility. The swelling behavior of the thermoresponsive microgel particles can be tuned by playing on two synthesis variables which are the initial solids content and the content of P(AETAC-X) macro-RAFT stabilizer. Furthermore, the inner structure of the synthesized microgels was probed by transverse relaxation nuclear magnetic resonance $\left(T_{2} \mathrm{NMR}\right)$ and small angle neutron scattering (SANS) measurements. The fit of $T_{2}$ NMR data confirmed a core-shell morphology with different crosslinking density in PVCL microgels. Through the determination of the network mesh size, SANS was suitable to explain the increase of the values of the PVCL microgel swelling ratios by increasing the initial solids content of their synthesis.

\section{INTRODUCTION}

Stimuli responsive polymers are polymers which respond to their environment by changing their physico-chemical properties. These polymers are designed to respond to external stimuli such as the temperature, electric or magnetic field, light, $\mathrm{pH}$, ionic strength, specific molecules or enzymes, among others. ${ }^{1,2}$ These polymers have received considerable attention within the last decade, due to their wide range of applications, especially in the biomedical field where they can be envisaged as potential drug delivery systems or biosensors. ${ }^{3-5}$ For such applications, stimuli-responsive microgels, i.e., crosslinked polymer particles able to reversibly swell in a good solvent and prevented from dissolution by cross-linking, are very promising candidates due to their tunable size, porosity and swelling profile. ${ }^{6-10}$ Special attention has been dedicated to thermoresponsive microgels that display a volume phase transition temperature (VPTT) in water, i.e., microgels that undergo a transition from a swollen to a collapsed state by increasing the temperature. ${ }^{11-15}$ Among the different thermoresponsive polymers available for the design 
of microgels, poly $(N$-vinylcaprolactam) (PVCL) appears to be a promising candidate because of its biocompatibility and its lower critical solution temperature of $32^{\circ} \mathrm{C}-38^{\circ} \mathrm{C}$, near to physiological temperature. ${ }^{16,17}$ Therefore, the synthesis of PVCL-based microgels has attracted a growing interest within the last years. ${ }^{18-34}$ The design of cationic thermoresponsive microgels is very attractive for various-applications. ${ }^{14}$ Indeed, cationic polymer particles are advantageous to interact favorably with negatively charged surfaces such as for instance cell surface or cellulosic surface. ${ }^{14,35}$ It was reported that the complexation with anionic bio-targets like DNA was relevant to facilitate cellular uptake for gene delivery. ${ }^{14,} 36$ Cationic PVCL-based thermosensitive microgels have been synthesized mainly by two strategies: 1) the use of either positively charged initiator or surfactant during the synthesis procedure, ${ }^{26,37}$ or 2) copolymerization of the main monomer with cationic co-monomers. ${ }^{20,21,38-40}$ In the first strategy, the content of cationic moiety is limited either by the low concentration of initiator fragment or by the low amount of molecular surfactant that should be limited to reduce toxicity. Regarding the second strategy, the introduction of cationic moieties into PVCL-based microgels led to a shift of the volume phase transition temperature towards higher values. ${ }^{20,41}$ Moreover, the amount of co-monomer and its distribution inside the network are parameters that play an important role in microgel swelling. ${ }^{42}$ Therefore, they should be carefully considered when designing cationic thermoresponsive microgels by copolymerization with a cationic co-monomer. It should be mentioned that for most of the examples, the solids content of the synthesized PVCL microgels/nanogels is limited to the range of 2 to $5 \mathrm{wt}-\%$. In the recent years, increasing attention has been focused on the use of reactive macromolecular stabilizers to synthesize thermoresponsive microgels by surfactant-free radical polymerization in aqueous dispersed-media. ${ }^{43-52}$ A macromolecular chain transfer agent efficient towards reversible addition fragmentation chain transfer (macroRAFT) or a macroalkoxyamine producing radicals by a reversible thermal equilibrium both promote the in-situ formation of amphiphilic 
copolymers during the course of the emulsion or aqueous dispersion polymerization. ${ }^{53-55}$ This approach rationalized as polymerization-induced self-assembly (PISA), ${ }^{53,55}$ proved its efficiency in increasing the solids content up to $10-20 \mathrm{wt}-\%$ for the synthesis of chemically ${ }^{46}$, 52 or physically ${ }^{56,57}$ crosslinked thermoresponsive particles in the absence of macroscopic gelation as the crosslinking step is confined in the core of the block copolymer assemblies. Moreover, using a hydrophilic polymer acting as both stabilizer and macromolecular control agent is a straightforward way to synthesize core/shell particles with functional macromolecular shell.

In the present work, we focused our attention on the synthesis of colloidally stable PVCLbased thermoresponsive microgels by batch emulsion polymerization of $N$-vinylcaprolactam by using reactive cationic macromolecular stabilizers synthesized by reversible addition fragmentation transfer (RAFT/MADIX) polymerization using a xanthate chain transfer agent (Scheme 1). The stabilization efficiency of the reactive cationic stabilizers is compared with the one of either non-reactive polymeric stabilizers or a conventional cationic molecular surfactant (cetyltrimethylammonium bromide). The influence of different synthesis variables (i.e, the concentrations of monomer and stabilizer) on both the colloidal features and the inner structure of the microgel particles is thoroughly investigated.

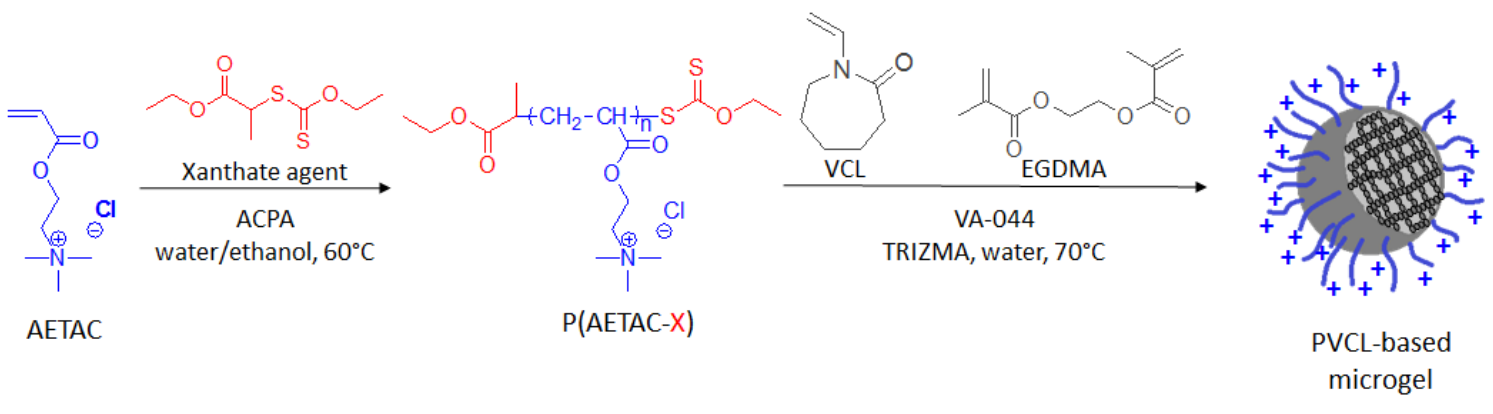

Scheme 1. RAFT/MADIX polymerization of AETAC to synthesize the reactive cationic polymers (P(AETAC-X)) used as reactive stabilizers for the synthesis of thermoresponsive PVCL-based microgel by emulsion polymerization. 


\section{EXPERIMENTAL SECTION}

\section{Materials}

$N$-Vinylcaprolactam (VCL, Sigma Aldrich, 98\%), ethylene glycol dimethacrylate (EGDMA, Sigma Aldrich, 98\%), potassium persulfate (KPS, Sigma Aldrich, 99\%), sodium bicarbonate ( $\mathrm{NaHCO}_{3}$, Sigma-Aldrich, 99.7\%), 2,2'-Azobis[2-(2-imidazolin-2-yl)propane] dihydrochloride (ADIBA or VA-044, Wako, 99\%), 4,4'-azobis(4-cyano)pentanoic acid (ACPA, Fluka, 98 \%), cetyltrimethylammonium bromide (CTAB, Sigma Aldrich, 99\%), tris(hydroxymethyl)aminomethane hydrochloride (TRIZMA, Sigma Aldrich, 99\%) and 1,3,5trioxane (Sigma Aldrich, 99\%) were used as received. [2(acryloyloxy)ethyl]trimethylammonium chloride solution (AETAC, Arkema, 98 wt-\% in water) was passed under inhibitors remover (Sigma Aldrich, $0.1 \mathrm{~g}$ in order to purify $50 \mathrm{~mL}$ of monomer) before use. Glycine buffer (Sigma Aldrich, $\mathrm{pH}$ 3) was used at ionic strength of 10 $\mathrm{mM}$ to control the $\mathrm{pH}$ for electrophoretic mobility measurements. Double deionized (DDI) water was used throughout the work.

Synthesis of P(AETAC-X) chain transfer agents and P(AETAC) polymer. In a typical experiment of the synthesis of P(AETAC-X) (Expt 3 in Table 1), $49.8 \mathrm{mg}$ of xanthate $(2.2 \times$ $\left.10^{-4} \mathrm{~mol}\right), 4.5 \mathrm{mg}$ of ACPA $\left(1.4 \times 10^{-5} \mathrm{~mol}\right), 3.0 \mathrm{~g}$ of AETAC $\left(1.6 \times 10^{-2} \mathrm{~mol}\right)$ and $142 \mathrm{mg}$ of trioxane $\left(1.6 \times 10^{-3} \mathrm{~mol}\right)$ were introduced in a $25 \mathrm{~mL}$ round bottom flask and dissolved in a mixture of $4.5 \mathrm{~g}$ of water and $0.5 \mathrm{~g}$ of ethanol $(90 / 10 \mathrm{wt}-\%)$. The reaction mixture was purged with nitrogen for 20 minutes at $0^{\circ} \mathrm{C}$, under stirring. A sample was withdrawn with a degazed syringe ( $t=0$ of the reaction). The flask was placed into an oil bath previously heated at $60^{\circ} \mathrm{C}$ and the reaction was allowed to continue for $6 \mathrm{~h}$. Samples were withdrawn with a degazed syringe at desired times. To stop the reaction, the flask was cooled down and oxygen was introduced. The polymer was then precipitated in cold THF and after elimination of the supernatant the obtained powder was dried under vacuum for one night. 


\section{Synthesis of PVCL-based microgels}

Microgels were synthesized by batch emulsion polymerization. For the synthesis of microgel particles stabilized by $\mathrm{P}(\mathrm{AETAC}-\mathrm{X})\left(\mathrm{SC} 1-\mathrm{PX} 764-\mathrm{E} 4\right.$ in Table 2), $2 \mathrm{~g}$ of VCL $\left(1.4 \times 10^{-2} \mathrm{~mol}\right)$, $0.08 \mathrm{~g}$ of $\mathrm{P}(\text { AETAC-X })_{76}(4 \mathrm{wt}-\%$ with respect to monomer $), 0.06 \mathrm{~g}$ of TRIZMA buffer $(3.7 \times$ $\left.10^{-4} \mathrm{~mol}\right), 0.13 \mathrm{~g}$ of 1,3,5-trioxane $\left(1.4 \times 10^{-3} \mathrm{~mol}\right)$ and $0.08 \mathrm{~g}$ of EGDMA $\left(4.2 \times 10^{-4} \mathrm{~mol}, 4\right.$ wt-\% with respect to VCL) were dissolved in $190 \mathrm{~g}$ of DDI water and placed into a $250 \mathrm{~mL}$ jacketed reactor, fitted with a reflux condenser, stainless steel stirrer, sample device, and nitrogen inlet tube reactor. The reaction mixture was purged with nitrogen for $30 \mathrm{~min}$ at room temperature and then for other 30 min during heating from $25^{\circ} \mathrm{C}$ to $70{ }^{\circ} \mathrm{C}$, at a stirring rate of $300 \mathrm{rpm}$. The cationic initiator was added under nitrogen flow at $70^{\circ} \mathrm{C}(0.02 \mathrm{~g}$ of ADIBA dissolved in $10 \mathrm{~g}$ of DDI water, $1 \mathrm{wt}-\%$ with respect to VCL, $6.5 \times 10^{-5} \mathrm{~mol}$ of ADIBA). The polymerization reaction was then allowed to continue with stirring for $4 \mathrm{~h}$ under nitrogen flow at $70^{\circ} \mathrm{C}$. The reaction mixture was subsequently cooled to $25^{\circ} \mathrm{C}$. The same procedure was applied for all the syntheses of PVCL-based microgels presented in this work.

The initial solids content $\tau$ is calculated as follows: $\tau=\left(\mathrm{m}_{\mathrm{VCL}} / \mathrm{m}_{\mathrm{water}}\right)_{0} \times 100$.

Table 2. Experimental conditions for the batch emulsion polymerization of VCL using $1 \mathrm{wt}-\%$ of ADIBA initiator based on VCL, 4 wt- $\%$ of EGDMA crosslinker based on VCL and 3 wt- $\%$ of TRIZMA buffer based on VCL. ${ }^{a}$

\begin{tabular}{cccc}
\hline Stabilizer & $\tau^{b}$ & Stabilizer & \\
& $w t-\%$ & $w t-\%$ Sample & \\
& & & \\
\hline
\end{tabular}




\begin{tabular}{|c|c|c|c|}
\hline $\mathrm{P}(\mathrm{AETAC}-\mathrm{X})_{76}$ & 1 & 4 & $\mathrm{SC} 1-\mathrm{PX}_{76} 4-\mathrm{E} 4$ \\
\hline $\mathrm{P}(\mathrm{AETAC}-\mathrm{X})_{76}$ & 1 & 8 & $\mathrm{SC} 1-\mathrm{PX}_{76} 8-\mathrm{E} 4$ \\
\hline $\mathrm{P}(\mathrm{AETAC}-\mathrm{X})_{16}$ & 1 & 4 & SC1-PX 16 4-E4 \\
\hline $\mathrm{P}(\mathrm{AETAC}-\mathrm{X})_{16}$ & 1 & 12 & SC1-PX 16 12-E4 \\
\hline $\mathrm{P}(\mathrm{AETAC}-\mathrm{X})_{9}$ & 1 & 4 & $\mathrm{SC} 1-\mathrm{PX} 94-\mathrm{E} 4$ \\
\hline $\mathrm{P}(\mathrm{AETAC}-\mathrm{X})_{76}$ & 5 & 4 & SC5-PX 76 4-E4 \\
\hline $\mathrm{P}(\mathrm{AETAC}-\mathrm{X})_{76}$ & 10 & 4 & SC10-PX 76 4-E4 \\
\hline $\mathrm{P}(\mathrm{AETAC}-\mathrm{X})_{9}$ & 5 & 4 & $\mathrm{SC}_{5-\mathrm{PX}} 94-\mathrm{E} 4$ \\
\hline
\end{tabular}

${ }^{a}$ Reaction conditions: $\mathrm{T}=70{ }^{\circ} \mathrm{C}, 300 \mathrm{rpm}$, reaction time $=4 \mathrm{~h} .{ }^{b}$ Initial solids content. ${ }^{c}$ Sample name: SC for initial solids content, the number following indicates the wt- $\%$ of VCL based on water $-\mathrm{PX}_{\mathrm{n}}$ : reactive cationic polymeric stabilizer with $n$ the degree of polymerization, the number following indicates the wt-\% of stabilizer based on VCL - E: EGDMA crosslinker, the number following indicates the wt-\% of EGDMA based on VCL.

\section{Characterizations of polymers and colloids}

Nuclear Magnetic Resonance (NMR) spectroscopy. Proton nuclear magnetic resonance spectroscopy $\left({ }^{1} \mathrm{H}\right.$ NMR) spectra were recorded on a Bruker $400 \mathrm{MHz}$ spectrometer at $25^{\circ} \mathrm{C}$. For the synthesis of $\mathrm{P}(\mathrm{AETAC}-\mathrm{X})$ macro-chain transfer agents and $\mathrm{P}(\mathrm{AETAC})$ polymer, monomer conversion was calculated from ${ }^{1} \mathrm{H}$ NMR spectra of the crude samples in DMSO- $d_{6}$ according to Equation 1.

$x_{\text {mono }}=1-\frac{\left({ }^{11 H_{\text {mono. }} / I 1 H_{\text {triox. }}}\right)_{t}}{\left({ }^{11 H_{\text {mono. }} / I 1 H_{\text {trio. }} .}\right)_{0}}$ Equation 1

$\mathrm{I}_{1 \mathrm{H} \text {,triox }}$ corresponds to the integral of 1,3,5-trioxane $(5.1 \mathrm{ppm}, 6 \mathrm{H})$ used as internal standard and $\mathrm{I}_{1 \mathrm{H}, \mathrm{mono}}$ corresponds to the integral of the vinylic proton of AETAC monomer at $6.0-6.4 \mathrm{ppm}$ (Figure S.1 in Supporting Information). 
For the microgel synthesis, monomer conversion was calculated from nuclear magnetic resonance spectra of the crude sample dispersed in $\mathrm{D}_{2} \mathrm{O}$, using 1,3,5-trioxane as internal standard according to Equation 1. $I_{1 \mathrm{H} \text {,triox }}$ corresponds to the integral of one proton of 1,3,5trioxane $(5.1 \mathrm{ppm}, 6 \mathrm{H})$ used as internal standard and $I_{1 \mathrm{H} \text {,mono }}$ corresponds either to the integration of the signal of VCL monomer at $7.1 \mathrm{ppm}$ or to the signal of EGDMA crosslinker at $6.2 \mathrm{ppm}$ (Figure S.2 in Supporting Information).

Diffusion ordered spectroscopy (DOSY) NMR measurements in $\mathrm{D}_{2} \mathrm{O}$ were performed using the bipolar longitudinal eddy current delay pulse sequence (BPLED). The spoil gradients were also applied at the diffusion period and the eddy current delay. Typically, a value of $2 \mathrm{~ms}$ was used for the gradient duration $(\delta), 150 \mathrm{~ms}$ for the diffusion time $(\Delta)$, and the gradient strength $(g)$ was varied from 1.67 G.cm ${ }^{-1}$ to 31.88 G.cm ${ }^{-1}$ in 32 steps. Each parameter was chosen to obtain 95\% signal attenuation for the slowest diffusion species at the last step experiment. The pulse repetition delay (including acquisition time) between each scan was larger than $2 \mathrm{~s}$. Data acquisition and analysis were performed using the Bruker Topspin software (version 2.1). The T1/T2 analysis module of Topspin was used to calculate the diffusion coefficients and to create 2-D spectra with NMR chemical shifts as one axis and the calculated diffusion coefficients along the second axis.

${ }^{1} \mathrm{H}$ transverse relaxation $\left(T_{2}\right)$ NMR measurements were carried out on a Bruker Avance 500 NMR spectrometer, using an already described protocol. ${ }^{25,}$ 26, 59 For these measurements, dialyzed microgel particles were centrifuged, freeze-dried and redispersed at $2 \mathrm{wt}-\%$ of solids content in deuterated water. For all measurements, the recycle delay time was $5 \mathrm{~s}$ and the dwell time was $10 \mu \mathrm{s}$. The decay of transverse magnetization relaxation was measured using the Hahn-echo pulse sequence: $90^{\circ}{ }^{-} t-180^{\circ}{ }^{-} t-\mathrm{Hahn}$ echo-(acquisition), where $t$ is the echo time. Half of the Hahn echo decay was detected and Fourier transformed. The normalized integral intensity of various resonances was fitted by two-exponential decay functions using OriginPro8 
program. The most intense resonance peak of PVCL that appears at $1.8 \mathrm{ppm}$ on the proton highresolution spectrum of the microgel ( $\mathrm{R}_{1}$, Figure S.3 in Supporting Information) is used for T2 NMR measurements to investigate the heterogeneity of the inner crosslinked structure of the synthesized microgels.

The bi-exponential decay of Equation 2 for the normalized integral of R1 proton resonance versus echo time was considered in Figure S.4 (Supporting Information) according to the following equation:

$\frac{S(t)}{S(0)}=C_{S} \exp \left\{-\frac{t}{T_{2 S}}\right\}+C_{L} \exp \left\{-\frac{t}{T_{2 L}}\right\}$ Equation 2

Where, $S(\mathrm{t}) / S(0)$ is the ratio between proton nuclear magnetic resonance transverse relaxation signal integral $(S)$ at time $t(S(\mathrm{t}))$ and at initial time $(S(0))$. This normalized $S(\mathrm{t}) / S(0)$ signal is plotted as a function of spin-echo time $t$ and $C_{\mathrm{i}}(\mathrm{i}=\mathrm{S}$ and $\mathrm{L})$ are the relative contribution of the decays characterized by short $\left(T_{2 \mathrm{~S}}\right)$ and long $\left(T_{2 \mathrm{~L}}\right)$ transverse relaxation times. The value of $T_{2 \mathrm{~S}}$ corresponds to a network with a higher value of the crosslinking density (core) as compared with $T_{2 \mathrm{~L}}$ (shell). The $C_{\mathrm{S}}$ and $C_{\mathrm{L}}$ coefficients are related to the number of protons in the methylene fragments of PVCL describing quantitatively the bimodal heterogeneity of the polymer network in microgel particles. The values of the short $\left(T_{2 \mathrm{~S}}\right)$ and long $\left(T_{2 \mathrm{~L}}\right)$ proton transverse relaxation times, and the relative amount of methylene protons of PVCL in core $\left(C_{\mathrm{S}}\right)$ and shell $\left(C_{\mathrm{L}}\right)$ were calculated from Equation 3 and reported in Table 6. Once short and long transverse relaxation times are obtained, the ratio of the crosslinking density of the microgel in core and shell $\left(\mathrm{CLD}^{\text {core }} / \mathrm{CLD}^{\text {shell }}\right)$ could be determined. ${ }^{25,26,59}$

$\frac{C L D^{\text {core }}}{C L D^{\text {shell }}}=\left(\frac{T_{2}^{\text {shell }}}{T_{2}^{\text {core }}}\right)^{1 / 2}$ Equation 3

Dynamic Light Scattering (DLS). Prior to colloidal characterization, the final microgel particles were dialyzed against distilled water for one week to remove unreacted reagents and impurities (Spectra/Por, $M_{\mathrm{w}}$ cut-off: $\left.12000-14000 \mathrm{Da}\right)$. The final average hydrodynamic diameters $\left(D_{\mathrm{h}}\right)$ 
of the microgels were measured by photon correlation spectroscopy (PCS) (or dynamic light scattering, DLS), using a Zetasizer Nano ZS instrument (Malvern Instruments). Measurements were carried out at a solids content of 0.005 wt $\%$ from $10^{\circ} \mathrm{C}$ to $55^{\circ} \mathrm{C}$, every to $2^{\circ} \mathrm{C}$, except between 30 and $40^{\circ} \mathrm{C}$ where measurements were recorded each $1{ }^{\circ} \mathrm{C}$. Before each scan, the sample was maintained at the set temperature for $10 \mathrm{~min}$. The hydrodynamic diameters reported in this chapter were measured before the dialysis step. Indeed, the average hydrodynamic diameters of the microgels measured before and after dialysis, as a function of the temperature are similar, as reported in Figure S.5 (Supporting Information). Regarding the determination of volume phase transition temperature (VPTT) values of the microgels, curves showing the evolution of the final hydrodynamic diameter as a function of the temperature are generally fitted using a Boltzmann function. The minimum of the fit first-order derivative is considered as the VPTT (Figure S.6 in Supporting Information).

The average number of microgel particles per liter of latex $\left(N_{\mathrm{p}}\right.$, particles. $\mathrm{L}^{-1}$ latex $)$ was calculated from the microgel average hydrodynamic diameter at the temperature of the collapsed state $\left(D_{\mathrm{h}}\right.$, $\left.55^{\circ} \mathrm{C}\right)$.

$N_{p}=\frac{6 \times \tau}{\pi \times\left(D_{h, 55^{\circ} C}\right)^{3} \times \rho_{\mathrm{PVCL}}}$ Equation 4

with $\tau$ : final solids content (g.L ${ }^{-1}$ latex $), \rho_{\mathrm{PVCL}}{ }^{60}=1.23 \mathrm{~g} \cdot \mathrm{cm}^{-3}$, and $D_{\mathrm{h}, 55^{\circ} \mathrm{C}}:$ microgel average hydrodynamic diameter at $55^{\circ} \mathrm{C}$.

Electrophoretic mobility measurements. Microgel electrophoretic mobility was measured using a Zetasizer Nano ZS instrument (Malvern Instruments). Dialyzed samples were diluted at 0.05 wt-\% in cationic buffer solution (glycine) at $\mathrm{pH} 3$ and ionic strength of $10 \mathrm{mM}$. Each sample was subjected to ten measurements at $25^{\circ} \mathrm{C}$, with a $60 \mathrm{~s}$ delay between each measurement. Transmission electron microscopy (TEM). Transmission electron microscopy (TEM) was used for the direct observation of the microgel particles. Images of the centrifuged microgels were 
recorded on a JEOL JEM 100CXII equipment, at $100 \mathrm{kV}$. Microgel dispersions were deposited on a copper grid and dried before analyses.

$U V$-Visible spectroscopy. The xanthate molecular chain-transfer agent, $\mathrm{P}(\mathrm{AETAC}-\mathrm{X})$ and P(AETAC) polymers were characterized by UV-Visible spectroscopy in a mixture of water:isopropanol (67:33 v:v\%), with a Shimadzu UV-2450PC spectrophotometer. The polymers were systematically precipitated once into THF prior characterization to remove any unreacted molecular CTA.

Asymmetric flow field-flow fractionation $(A-4 F)$. A-4F analyses were carried out on a AF4 Wyatt Eclipse 3 system, equipped with a RI detector Optilab T-rEX from Wyatt and Wyatt Dawn Heleos II MALLS detector $\left(\lambda_{0}=658 \mathrm{~nm}\right)$. Dimension of the channel: $290 \times 70 \times 50$ $\mathrm{mm}$; injection volume: $50 \mu \mathrm{L}$; focus flow rate: $3 \mathrm{~mL} \cdot \mathrm{min}^{-1}$; detector flow rate: $1.0 \mathrm{~mL} \cdot \mathrm{min}^{-1}$; cross-flow rate: $3 \mathrm{~mL} \cdot \mathrm{min}^{-1}$. For all experiments, poly(ether sulfone) (PES) membranes with a $5 \mathrm{kDa}$ molecular weight cutoff were used. Ultrapure water supplemented with $0.03 \mathrm{wt}-\%(5 \times$ $10^{-3}$ mol. $\mathrm{L}^{-1}$ ) of sodium azide $\mathrm{NaN}_{3}$ salt was used as eluent. Polymer samples were prepared at a concentration of $6 \mathrm{mg} \cdot \mathrm{mL}^{-1}$.

Small Angle Neutron Scattering (SANS). The microgels were dissolved in deuterated water $\left(\mathrm{D}_{2} \mathrm{O}, 99,9 \%\right.$ D, Eurisotop) at 20 g.L ${ }^{-1}$. SANS measurements were performed on PAXY spectrometer at Laboratoire Léon Brillouin (LLB) (Saclay, France). The scattered intensity was measured over a wide range of scattering vectors $q$, between $0.002 \AA^{-1}$ and $0.4 \AA^{-1}$, using three configurations ( $D=1 \mathrm{~m}, l=6 \AA ; D=3 \mathrm{~m}, l=6 \AA ; D=7 \mathrm{~m}, l=15 \AA$ ) where $D$ and $l$ are the sample-to-detector distance and the neutron wavelength respectively. The scattered intensity was corrected for empty cell scattering and incoherent background and set on an absolute scale according to standard procedures. ${ }^{61}$ All samples were measured in $1 \mathrm{~mm}$ quartz cells at $10^{\circ} \mathrm{C}$ and $50^{\circ} \mathrm{C} . \mathrm{H}_{2} \mathrm{O}$ measured in a $1 \mathrm{~mm}$ thick cell was used as calibration standard. All the intensities were measured in absolute units $\left(\mathrm{cm}^{-1}\right)$. Data were processed by the PASINET software. ${ }^{61}$ The 
adjustments were performed using the SASVIEW software (http://www.sasview.org). SANS curves recorded at $\mathrm{T}=10^{\circ} \mathrm{C}$ were fitted with a Sphere Model (Equation 5) ${ }^{62}$ at low $q$-range $\left(\sim 0.002-0.1 \AA^{-1}\right)$ and Lorentz (Ornstein-Zernicke Model) (Equation 6) at high $q$-range $(\sim 0.1$ $0.4 \AA^{-1}$ ) while the SANS curves measured at $50{ }^{\circ} \mathrm{C}$ were fitted only with the sphere model.

$I(q)=\frac{\text { scale }}{V}\left[\frac{3 V(\Delta \rho)(\sin (q r)-q r \cos (q r))}{(q r)^{3}}\right]^{2}+b k g$ Equation 5

In Equation 5 and Equation 6, scale is the volume fraction, $V$ is the volume of the scatterer, $r$ is the radius of the sphere, $b k g$ is the background level, $\Delta \rho$ is the difference between the scatterer and solvent scattering length density (SLD), $\xi$ is the mesh size.

$I(q)=\frac{\text { scale }}{1+(q \xi)^{2}}+b k g$ Equation 6

\section{RESULTS AND DISCUSSION}

\section{Synthesis of the cationic polymeric stabilizers by RAFT polymerization.}

A series of three reactive cationic polymers of [2-(Acryloyloxy)ethyl]trimethylammonium chloride $\left(\mathrm{P}(\text { AETAC-X })_{\mathrm{n}}\right)$ with varying degree of polymerization $(n)$ (Table 1) were synthesized by RAFT/MADIX polymerization (Scheme 1). These polymers were used as reactive stabilizers for the subsequent synthesis of PVCL-based microgels by emulsion polymerization. Apart from this series, two non-reactive cationic polymers were also prepared, either by freeradical polymerization $(\mathrm{P}(\mathrm{AETAC}))$ or by cleavage of the chain-end of a xanthatefunctionalized polymer (P(AETAC-X)76, cleaved). The efficiency of a hydrophilic polymer to act as a reactive stabilizer depends on its ability to promote transfer reactions with the PVCL growing chains during the early stages of the emulsion polymerization. The evolution of the logarithmic conversion $(x)$ of AETAC versus time is displayed in Figure S.7 in Supporting Information for the synthesis of $\mathrm{P}(\mathrm{AETAC}-\mathrm{X})_{76}$ by RAFT polymerization (see Expt 3 in Table 1). The results display an inhibition period of 30 minutes before to reach a complete conversion 
of monomer after 6 hours. The linear increase of the logarithmic monomer conversion is characteristic of a constant concentration of radicals along the polymerization correlated with few occurrence of irreversible termination reactions. The polymers of Table $\mathbf{1}$ were characterized by UV-visible spectroscopy after precipitation in THF. Figure $\mathbf{1}$ displays the spectra of the xanthate RAFT agent together with the overlay of the different cationic $\mathrm{P}(\mathrm{AETAC})$ to be compared. Two resonance bands at wavelengths of $306 \mathrm{~nm}$ and $355 \mathrm{~nm}$ were characteristic of the xanthate (dithiocarbonate) chemical group together with an intense absorption between 200 and $280 \mathrm{~nm}$ (Figure 1). Both P(AETAC-X) polymers synthesized by RAFT polymerization exhibit the characteristic bands of the xanthate (dithiocarbonate) chemical group at 306 and $355 \mathrm{~nm}$ (Figure 1) while these bands are absent in the UV-visible spectrum of the $\mathrm{P}(\mathrm{AETAC})$ synthesized by free radical polymerization in the absence of xanthate CTA (expt 4 Table 1 and Figure 1). The intensity of the characteristic bands of the xanthate chain-end at $306 \mathrm{~nm}$ and $355 \mathrm{~nm}$ drastically decreased for the P(AETAC-X) 76 , cleaved prepared by cleavage of the xanthate chain-end of the functional $\mathrm{P}(\mathrm{AETAC}-\mathrm{X})_{76}$ polymer using a 20-fold excess of ADIBA initiator (see P(AETAC-X)76, cleaved, Figure 1). Moreover, the narrow band at $250 \mathrm{~nm}$ was observed only for the $\mathrm{P}\left(\right.$ AETAC) and $\mathrm{P}(\mathrm{AETAC}-\mathrm{X})_{76}$, cleaved (Figure 1) whereas the absorbance of the xanthate group hides this band in the $\mathrm{P}(\mathrm{AETAC}-\mathrm{X})_{76}$ spectrum. These results confirm the presence of the xanthate chain-end in the $\mathrm{P}(\mathrm{AETAC}-\mathrm{X})_{76}$ synthesized by RAFT polymerization. Consequently, the P(AETAC-X) cationic polymers synthesized by RAFT polymerization will be considered as reactive polyelectrolyte stabilizers towards the radical emulsion polymerization of VCL monomer for the synthesis of thermoresponsive microgels. 

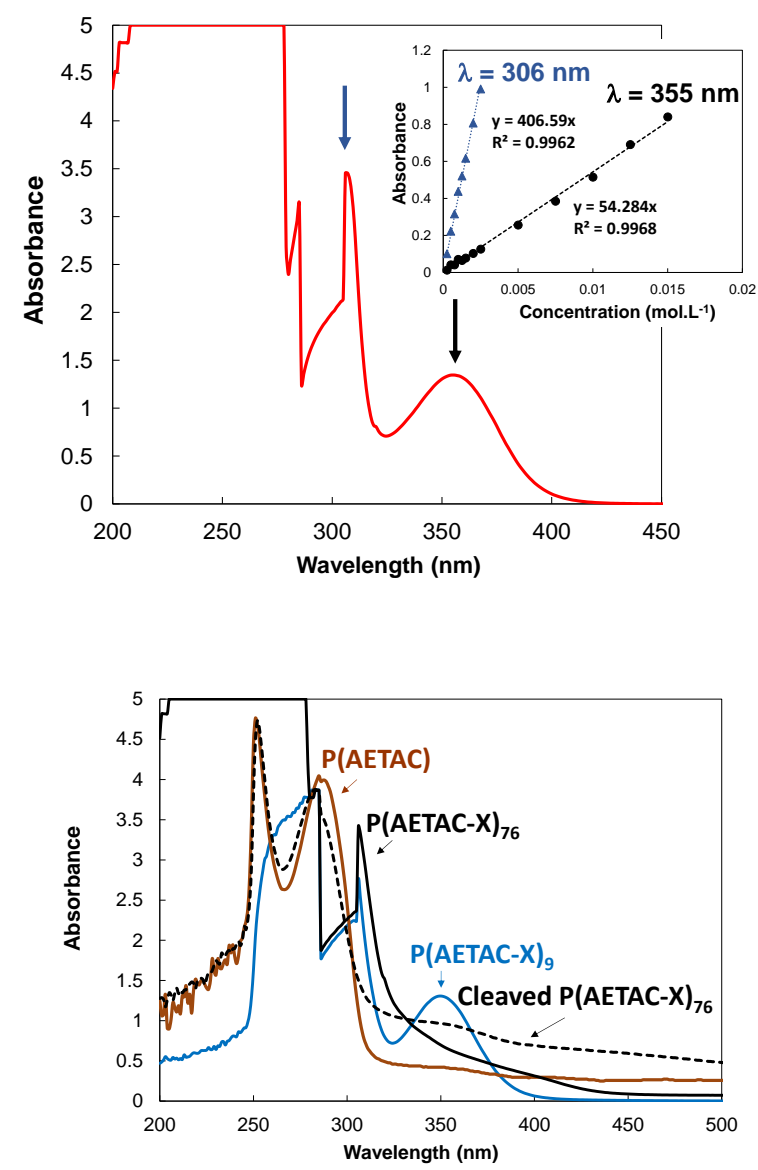

Figure 1. Top: UV-visible spectrum of xanthate agent in a mixture of water:isopropanol (67:33 v:v\%) (zoom: absorbance versus concentration for both wavelengths of $306 \mathrm{~nm}$ and $355 \mathrm{~nm}$ ); Bottom: UV-visible spectra of $\mathrm{P}(\mathrm{AETAC}-\mathrm{X})_{\mathrm{n}}$ (black and blue plain lines, respectively expt 3 $(n=76)$ and $1(n=9)$ in Table 1$), \mathrm{P}(\text { AETAC-X })_{76, \text { cleaved (dashed black line) and P(AETAC) }}$ (brown plain line, expt 4 in Table 1). Polymers in a mixture of water:isopropanol (67:33 v:v\%). $\left[\mathrm{P}(\text { AETAC-X })_{76}\right]=212 \mathrm{~g} \cdot \mathrm{L}^{-1},\left[\mathrm{P}(\text { AETAC-X })_{9}\right]=28 \mathrm{~g} \cdot \mathrm{L}^{-1},[\mathrm{P}($ AETAC $)]=71 \mathrm{~g} \cdot \mathrm{L}^{-1}$ and $\left[\mathrm{P}(\text { AETAC })_{76, \text { cleaved }}\right]=84 \mathrm{~g} \cdot \mathrm{L}^{-1}$.

The fraction of additional dead polymer chains $(F)$ that do not carry thiocarbonylthio end group can be calculated from the number of chains created by the initiator (Equation 7). It can be noticed that the theoretical values of $F$ are below 3 mol-\% (Table 3). 
$F=\frac{[A C P A] 0 \times\left(1-e^{-k_{d} \times t}\right)}{([\text { xanthate }])} \quad$ Equation 7

In Equation $7, k_{\mathrm{d}}$ corresponds to the dissociation rate constant of the initiator $\left(k_{\mathrm{d}, \mathrm{ACPA}}\right.$, water, $70^{\circ} \mathrm{C}$ $\left.=2.2 \times 10^{-5} \mathrm{~s}^{-1}\right) .^{63}$ The number-average molar masses $\left(M_{\mathrm{n}}\right)$ of the $\mathrm{P}(\mathrm{AETAC}-\mathrm{X})$ cationic polymers were calculated from the UV-visible spectra of polymers on the basis of Equation 8. In this calculation, we considered the ratio between the mass of polymer (= mass of monomer units) and the number of moles of dithiocarbonate chain-end calculated from Beer-Lambert relationship $\left(n_{\text {xanthate }}=(\right.$ Absorbance $\left.\times V) / \varepsilon_{\text {xanthate }}\right)$.

$M \mathrm{n}_{\mathrm{UV}}=\frac{m_{\text {polymer }}}{n_{\text {xanthate }}+F \times n_{\text {xanthate }}}\left(\mathrm{g} \cdot \mathrm{mol}^{-1}\right)$ Equation 8

The determination of the experimental molar masses of the $\mathrm{P}(\mathrm{AETAC}-\mathrm{X})$ polymers by UVvisible spectroscopy is based on the assumption that each polymer chain contains a xanthate chain-end, apart from the fraction of dead chains $(\mathrm{F})$ considered in Equation 8. As reported in Table 3, the experimental $M_{\mathrm{n}, \mathrm{UV}}$ based on UV-visible spectroscopy are in the range of the theoretical $M_{\mathrm{n}}$ calculated from Equation 9 and $M_{\mathrm{n}, \mathrm{UV}}$ increases by decreasing the initial concentration of the xanthate chain transfer agent.

$M \mathrm{n}_{\text {theo. }}=M_{\text {xanthate }}+\frac{[\mathrm{AETAC}]_{0}}{\left([\text { xanthate }] 0+[\mathrm{ACPA}] 0 \times\left(1-\mathrm{e}^{-\mathrm{k}_{\mathrm{d}} \mathrm{t}}\right)\right)} \times$ conv. $\times M_{\text {AETAC }} \quad$ Equation 9

Table 3. Macromolecular features of P(AETAC-X) cationic polymers synthesized by RAFT/MADIX polymerization.

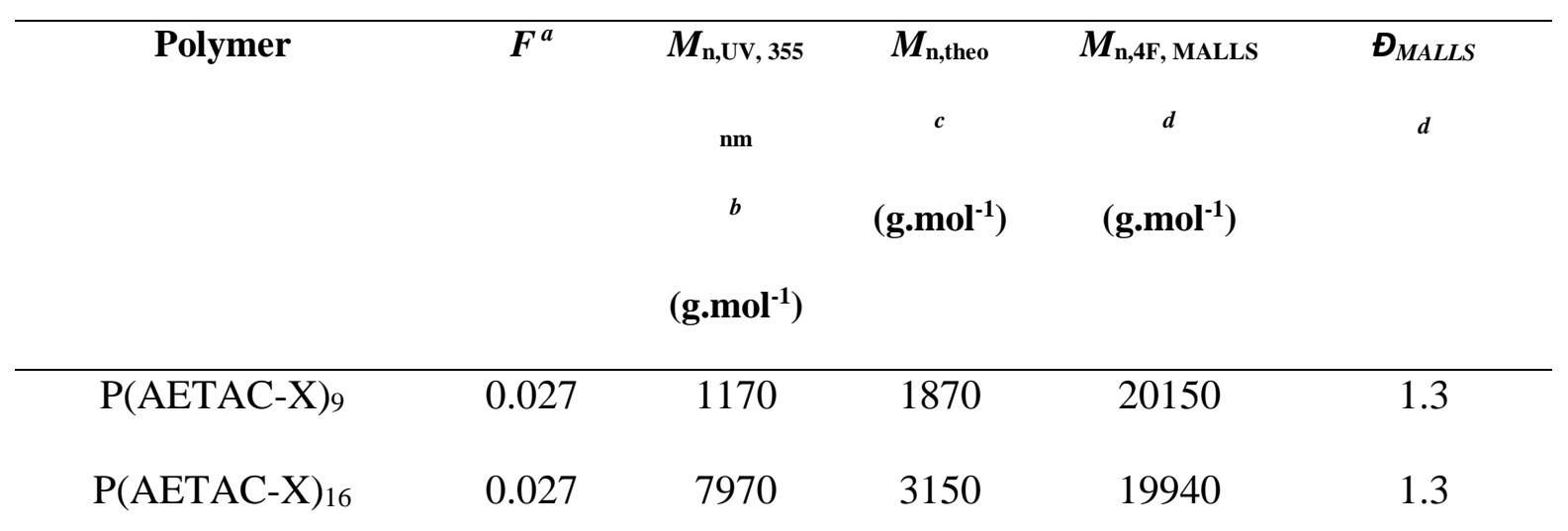




$$
\begin{array}{llllll}
\mathrm{P}(\mathrm{AETAC}-\mathrm{X})_{76} & 0.025 & 17530 & 14450 & 92130 & 1.2
\end{array}
$$

$\overline{{ }^{a}}$ Theoretical fraction of dead polymer chain (see Equation 7). ${ }^{b}$ Experimental $M_{\mathrm{n}}$ calculated from UV-absorbance at $t=6 \mathrm{~h}$ from absorbance of $\mathrm{P}\left(\right.$ AETAC-X) at $355 \mathrm{~nm}\left(\mathrm{~A}_{355 \mathrm{~nm}}<1\right)$ with $\varepsilon_{\text {xanthate, }} 355 \mathrm{~nm}=54 \mathrm{~L} \cdot \mathrm{mol}^{-1} \cdot \mathrm{cm}^{-1}$ (Figure 1). ${ }^{c}$ Theoretical $M_{\mathrm{n}}$ calculated at $t=6 \mathrm{~h}$ (see Equation 9). ${ }^{d}$ Values obtained from the A-4F analysis with a MALLS detector, using $(\mathrm{d} n / \mathrm{d} c)_{\mathrm{P}(\mathrm{AETAC}-\mathrm{X}) \mathrm{n}}=0.137$ $\mathrm{mL} \cdot \mathrm{g}^{-1}$.

Concomitantly, the series of $\mathrm{P}(\mathrm{AETAC}-\mathrm{X})$ polymers were characterized by asymmetrical field flow fractionation equipped with a multi-angle laser light scattering detector (MALLS) to provide the number-average molar masses of the $\mathrm{P}(\mathrm{AETAC}-\mathrm{X})_{\mathrm{n}}\left(M_{\mathrm{n}, \mathrm{MALLS}}\right)$. It can be noticed first that values of $M_{\mathrm{n}, \mathrm{MALLS}}$ follow the trend of theoretical ones calculated from Equation 9, i.e., $M_{\mathrm{n}, \mathrm{MALLS}}$ decreases by decreasing the theoretical degree of polymerization $n$ of the $\mathrm{P}(\mathrm{AETAC}-\mathrm{X})_{n}($ Table 3).

This trend highlights the ability of the xanthate chain transfer agent to tune the experimental $M_{\mathrm{n}}$ of the $\mathrm{P}(\mathrm{AETAC}-\mathrm{X})$ polymers. Moreover, the low dispersity values $(1.2<Ð<1.3)$ of the P(AETAC-X) confirm a control of polymer growth (see examples of fractograms in Figure S.8 in Supporting Information). However, all the series of P(AETAC-X) exhibits experimental $M_{\mathrm{n}, \mathrm{MALLS}}$ values approximately 10 times higher than both the experimental $M_{\mathrm{n}, \mathrm{UV}}$ and the theoretical $M_{\mathrm{n}}$ calculated from Equation 9 (see Table 3). By taking into account the experimental values of $M_{\mathrm{n}, \mathrm{MALLS}}$ and the number of moles of xanthate calculated from the absorbance, the number of xanthate function per analyzed polymer is particularly high which is not conceivable from the synthesis viewpoint. This result might highlight aggregation of P(AETAC-X) chains in water. The aqueous solutions of $\mathrm{P}(\mathrm{AETAC}-\mathrm{X})$ polymers were characterized by different methods (DOSY NMR, dynamic light scattering and SEC) which converged to show that such polymers composed of a hydrophobic backbone and hydrophilic cationic side chains tend to 
aggregate. This study is beyond the topic of the present article but we summarize the different observations: 1) the $\mathrm{P}(\text { AETAC-X })_{76}$ polymer solubilized in $\mathrm{D}_{2} \mathrm{O}$ or in $0.1 \mathrm{M} \mathrm{NaCl}$ in $\mathrm{D}_{2} \mathrm{O}$ displayed two diffusion coefficients in the DOSY NMR spectra suggesting aggregates (Figure S.9 in Supporting Information), 2) the analysis of $\mathrm{P}(\mathrm{AETAC}-\mathrm{X})_{76}$ polymer by aqueous size exclusion chromatography exhibited $M_{\mathrm{n}}$ values above $10^{6} \mathrm{~g} \cdot \mathrm{mol}^{-1}$ with high gyration radius of $50 \mathrm{~nm}$, far above the $M_{\mathrm{n}}$ values measured by A4F suggesting aggregation in the experimental set up of SEC analysis (Figure S.10 in Supporting Information), 3) the appearance of an angular dependence of the hydrodynamic diameter for increasing concentrations of $\mathrm{P}(\mathrm{AETAC}-\mathrm{X})$ in saline aqueous solutions (Figure S.11 in Supporting Information) evidenced intermolecular interactions as previously described by Förster et al.. ${ }^{64}$

In conclusion of this part, a series of the cationic $\mathrm{P}(\mathrm{AETAC}-\mathrm{X})_{\mathrm{n}}$ with varying degrees of polymerization were synthesized as reactive stabilizers for the subsequent synthesis of PVCLbased microgels by emulsion polymerization. Apart from this series, two non-reactive cationic polymers were prepared, either by free-radical polymerization (P(AETAC)) or by cleavage of a xanthate-functionalized polymer $(\mathrm{P}($ AETAC-X $) 76$, cleaved $)$ in order to compare their stabilization efficiency with the reactive xanthate end-functionalized $\mathrm{P}(\mathrm{AETAC}-\mathrm{X})_{\mathrm{n}}$ cationic polymers.

\section{Synthesis and characterization of thermoresponsive PVCL-based microgels.}

For all the experiments presented in this section, reproducibility was assessed performing each experiment twice. The optimum experimental variables to produce stable PVCL-based microgels stabilized by the $\mathrm{P}(\mathrm{AETAC}-\mathrm{X})$ cationic polymers by batch emulsion polymerization of VCL carried out at $1 \mathrm{wt}-\%$ of initial solids content were set: TRIZMA buffer with ADIBA initiator at a molar ratio of 6 , a concentration of $1 \mathrm{wt}-\%$ of ADIBA initiator based on VCL, a 
temperature of $70^{\circ} \mathrm{C}$ and a minimum level of cationic stabilizer of 4 wt- $\%$ based on VCL. For these polymerizations, a complete monomer conversion is reached within 40 minutes (Figure S.12 in Supporting information) while maintaining stability of the final microgel dispersion. The swelling-to-collapse transition is reversible in the absence of any hysteresis (Figure S. 5 in Supporting information) which features a narrow particle size distribution. Indeed, well-defined spherical, monodisperse PVCL-based microgels were observed by transmission electron microscopy (TEM) (Figure 2). The values of the volume phase transition temperature (VPTT) ranged between $28{ }^{\circ} \mathrm{C}$ and $30^{\circ} \mathrm{C}$ (see Table 4). These values are in accordance with the range of VPTT previously reported for PVCL-based microgels. ${ }^{22,23,26,65}$
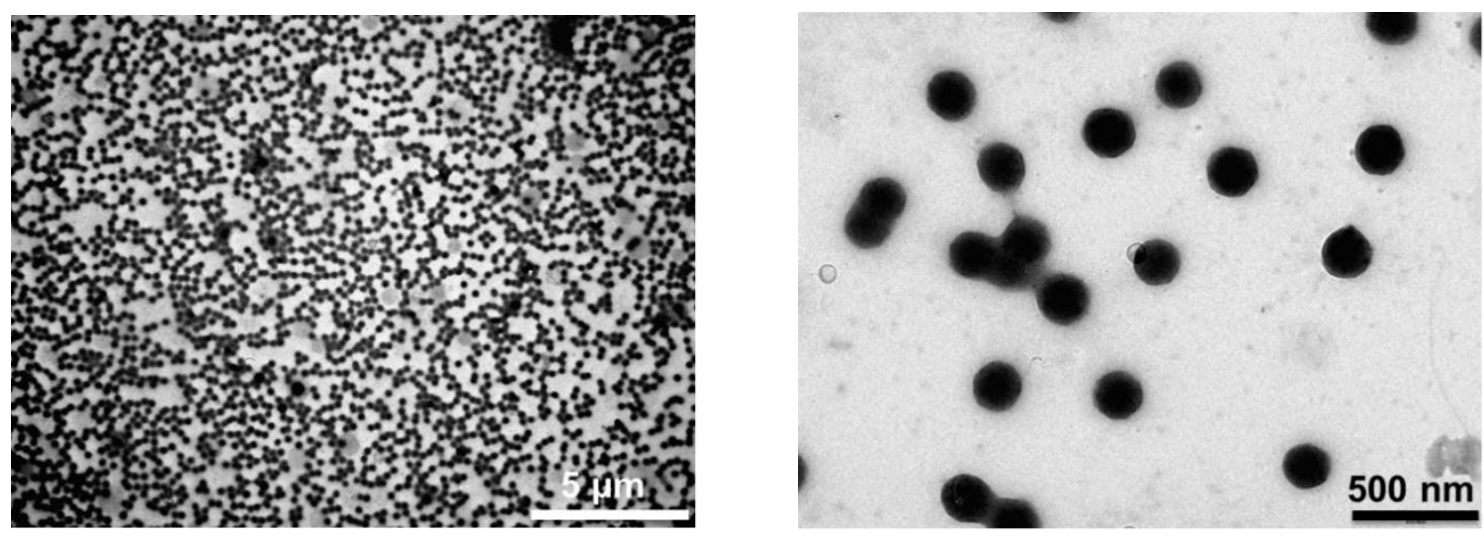

Figure 2. TEM images of the microgels synthesized at $5 \mathrm{wt}-\%$ of initial solids content and $4 \mathrm{wt}-$ $\%$ of $\mathrm{P}(\mathrm{AETAC}-\mathrm{X})_{76}$ stabilizer with respect to VCL $\left(\mathrm{SC}^{-\mathrm{PX}} \mathrm{P}_{76} 4-\mathrm{E} 4\right.$ in Table 4).

The volume-average diameter $\left(D_{\mathrm{v}}\right)$ was calculated from the TEM images on the basis of 200 particles using Equation 10.

$\left\langle D_{\mathrm{v}}\right\rangle=\bar{D}_{v}=\left(\frac{\sum n_{i} D_{i}^{3}}{\sum n_{i}}\right)^{\frac{1}{3}}$ Equation 10

The volume-average diameter of the dried SC5-PX 76 -E4 microgels $\left(D_{\mathrm{v}}=292 \pm 18 \mathrm{~nm}\right.$, Figure 2), is in a similar range as the average hydrodynamic diameter of the microgels measured by DLS at the collapsed state $\left(D_{\mathrm{h}, 55^{\circ} \mathrm{C}}=214 \pm 5 \mathrm{~nm}, \mathrm{SC} 5-\mathrm{PX} 76\right.$ 4-E4 in Table 4). Since the PVCL- 
based microgels are soft particles, they have tendency to spread on the surface during the drying process prior the TEM analysis and therefore the $D_{\mathrm{v}}$ calculated from TEM images are higher than $D_{\mathrm{h}, 55^{\circ} \mathrm{C}}$ measured by DLS. ${ }^{66}$

Table 4. Colloidal features of stable PVCL-based microgels synthesized at $70^{\circ} \mathrm{C}$ by using $\mathrm{P}(\mathrm{AETAC}-$ X) stabilizer. ${ }^{\mathrm{a}}$

\begin{tabular}{|c|c|c|c|c|}
\hline Reaction & $\begin{array}{c}\boldsymbol{D}_{\mathbf{h}, \mathbf{5 5}{ }^{\circ} \mathbf{C}} \\
n m\end{array}$ & $\begin{array}{c}N_{\mathbf{p}} \times 10^{15} \\
L_{\text {latex }}{ }^{b}\end{array}$ & $\begin{array}{c}\boldsymbol{D}_{\mathbf{h}, 10^{\circ} \mathbf{C}} \\
n m\end{array}$ & $\begin{array}{c}\text { VPTT }^{\mathbf{c}} \\
{ }^{\circ} \mathrm{C}\end{array}$ \\
\hline SC1-PX 76 4-E4 & $169 \pm 15$ & $3.4 \pm 1.1$ & $309 \pm 4$ & $28.2 \pm 1.1$ \\
\hline $\mathrm{SC} 1-\mathrm{PX} 76$ 8-E4 & $170 \pm 31$ & $3.6 \pm 2.3$ & $238 \pm 8$ & $30.9 \pm 0.2$ \\
\hline SC1-PX 16 4-E4 & $221 \pm 33$ & $1.0 \pm 0.8$ & $397 \pm 40$ & $30.8 \pm 3.1$ \\
\hline SC1-PX 16 12-E4 & $155 \pm 7$ & $4.2 \pm 0.6$ & $154 \pm 12$ & - \\
\hline SC1-PX $94-E 4$ & $156 \pm 2$ & $4.1 \pm 0.2$ & $330 \pm 17$ & $30.2 \pm 0.6$ \\
\hline $\mathrm{SC}-\mathrm{PX}{ }_{76} 4-\mathrm{E} 4$ & $214 \pm 5$ & $8.0 \pm 0.6$ & $769 \pm 41$ & $30.7 \pm 0.6$ \\
\hline SC10-PX 76 4-E4 & $215 \pm 34$ & $18.0 \pm 1.0$ & $741 \pm 84$ & $30.6 \pm 2.0$ \\
\hline $\mathrm{SC}_{5-\mathrm{PX}} 94-\mathrm{E} 4$ & $200 \pm 2$ & $9.7 \pm 0.3$ & $642 \pm 20$ & $30.6 \pm 1.5$ \\
\hline
\end{tabular}

${ }^{a}$ Reaction conditions: $\mathrm{rpm}=300$, reaction temperature $=70^{\circ} \mathrm{C}$; reaction time $=4 \mathrm{~h}, 1 \mathrm{wt}-\%$ of ADIBA initiator based on VCL and 3 wt-\% of TRIZMA buffer based on VCL. The final conversion of VCL determined by ${ }^{1} \mathrm{H}$ NMR ranged between 96 and $100 \%$ for all experiments. ${ }^{b}$ Average number of particles measured from $D_{\mathrm{h}}$ at $55^{\circ} \mathrm{C}$, Equation $4 ;{ }^{\mathrm{c}}$ Volume Phase Transition Temperature.

1. Influence of the nature of the stabilizer on the colloidal stability of PVCL-based microgels. The stabilization efficiency of different stabilizers was analyzed in order to investigate the role of the reactive xanthate chain-end of the cationic $\mathrm{P}(\mathrm{AETAC}-\mathrm{X})$ macromolecular stabilizer (Table 5). For this purpose, polymerizations of VCL in aqueous dispersed media were carried 
out at solids content ranging from 1 to $10 \mathrm{wt}-\%$ in the presence of the following different stabilizers (see Figure S.13 in Supporting information: i) a reactive P(AETAC-X) ${ }_{76}$ polymer synthesized by RAFT/MADIX polymerization (Table 1); ii) two non-reactive P(AETAC) polymers, one $\mathrm{P}(\mathrm{AETAC})$ synthesized by free radical polymerization in the absence of control agent, and one $\mathrm{P}(\mathrm{AETAC}-\mathrm{X})_{76}$, cleaved prepared by cleavage of the xanthate chain-end of $\mathrm{P}(\mathrm{AETAC}-\mathrm{X})_{76}$; iii) a conventional cationic molecular surfactant (cetyltrimethylammonium bromide, CTAB). As a matter of comparison, a series of PVCL-based microgels was also synthesized in the absence of any additional cationic stabilizer. The results are gathered in

\section{Table 5.}

Table 5. Results for PVCL-based microgels synthesized by polymerization in aqueous dispersed media using different types of stabilizers, $1 \mathrm{wt}-\%$ of ADIBA initiator based on VCL, 4 wt- $\%$ of EGDMA based on VCL and 3 wt- $\%$ of TRIZMA buffer based on VCL. ${ }^{a}$

\begin{tabular}{|c|c|c|c|c|}
\hline \multirow{2}{*}{$\begin{array}{l}\text { Solids } \\
\text { content } \\
\text { (wt-\%) }\end{array}$} & \multicolumn{4}{|c|}{ Stabilizer } \\
\hline & Initiator fragment & CTAB & $\begin{array}{c}\text { Non- reactive } \\
\text { P(AETAC) }\end{array}$ & $\begin{array}{c}\text { Reactive } \\
\text { P(AETAC-X })_{76}\end{array}$ \\
\hline \multirow[t]{2}{*}{1} & Flocculation & Aggregation & Flocculation $^{c}$ & Stable dispersion \\
\hline & $S C 1-0-E 4$ & SC1-CTAB 4-E4 & $S C 1-P X_{76, \text { cleaved }} 4-E 4$ & $S C 1-P X_{76} 4-E 4$ \\
\hline \multirow[t]{2}{*}{5} & 65 wt- $\%$ Coagulum ${ }^{b}$ & 49 wt- $\%$ Coagulum & 50 wt- $\%$ Coagulum ${ }^{d}$ & Stable dispersion \\
\hline & SC5-0-E4 & SC5-CTAB 4-E4 & SC5-P 4-E4 & $S C 5-P X_{76} 4-E 4$ \\
\hline \multirow[t]{2}{*}{10} & $n a$ & 35 wt- $\%$ Coagulum & 30 wt- $\%$ Coagulum ${ }^{d}$ & Stable dispersion \\
\hline & & SC10-CTAB 4-E4 & SC10-P 4-E4 & $S C 10-P X_{76} 4-E 4$ \\
\hline \multicolumn{5}{|c|}{${ }^{a}$ Reaction conditions: $\mathrm{rpm}=300$; reaction temperature $=70^{\circ} \mathrm{C}$; reaction time $=4 \mathrm{~h}$. The final } \\
\hline
\end{tabular}


reactive $\mathrm{P}(\mathrm{AETAC}-\mathrm{X})_{76}$, cleaved as stabilizer; ${ }^{d}$ Experiments performed using non-reactive $\mathrm{P}(\mathrm{AETAC})$ synthesized by free radical polymerization as stabilizer.

The microgel synthesized in the absence of cationic stabilizer, at $1 \mathrm{wt}-\%$ of initial solids content (SC1-0-E4 in Table 5), undergoes flocculation upon cooling, i.e., a reversible coagulation of the particles was observed when the dispersion was cooled down but the microgels were able to redisperse in the aqueous phase (see Figure S.14a in Supporting Information). For the microgel synthesized at $1 \mathrm{wt}-\%$ of initial solids content with CTAB surfactant (SC1-CTAB 4E4 in Table 5), the average hydrodynamic diameter measured by DLS analysis was higher at $55^{\circ} \mathrm{C}$ than at $10^{\circ} \mathrm{C}$, traducing the formation of particle aggregates above the VPTT (see Figure S.14 in Supporting Information). For a dispersion of PVCL-based microgels stabilized by the non-reactive $\mathrm{P}(\mathrm{AETAC}-\mathrm{X})_{76}$, cleaved polymer (SC1-PX 76 ,cleaved 4-E4 in Table 5), a microgel flocculation is observed upon cooling of the dispersion, as for the microgels synthesized in the absence of stabilizer. For experiments carried out at $1 \mathrm{wt}-\%$ of initial solids content, stable PVCL-based microgels were obtained only with the reactive $\mathrm{P}(\mathrm{AETAC}-\mathrm{X})$ as stabilizer (SC1$\mathrm{PX}_{76} 4$-E4 in Table 5). Increasing the initial solids content up to $5 \mathrm{wt}-\%$ led to the formation of 50 to $65 \mathrm{wt}-\%$ of coagulum (i.e., macroscopic precipitated polymer, see Figure S.14 in Supporting Information) for emulsion polymerization carried out in the absence of cationic stabilizer or surfactant (SC5-0-E4 in Table 5) or for emulsion polymerizations stabilized either by CTAB surfactant or by the non-reactive P(AETAC) macromolecular stabilizer (respectively SC5-CTAB 4-E4 and SC5-P 4-E4 in Table 5). On the other hand, for the all range of initial solids content (1 to $10 \mathrm{wt}-\%$ ), stable PVCL-based microgels free of flocculation or coagulum were synthesized in the presence of the reactive $\mathrm{P}(\mathrm{AETAC}-\mathrm{X})_{76}$ as stabilizer $(\mathrm{SC} 1-\mathrm{PX} 76$ 4-E4, SC5-PX 76 4-E4 and SC10-PX 76 4-E4 in Table 5). These results highlight the key role played by the reactive xanthate chain-end of the cationic $\mathrm{P}($ AETAC-X) in the stabilization of 
microgels, which offers the opportunity to synthesize for the first time stable PVCL-based microgels up to $10 \mathrm{wt}-\%$ of initial solids content $\left(\mathrm{SC}_{10-\mathrm{PX}} \mathrm{76} 4-\mathrm{E} 4\right.$ in Table 5). Note that the reactive $\mathrm{P}(\mathrm{AETAC}-\mathrm{X})_{9}$ with a lower theoretical degree of polymerization decreased the particle size in comparison with the $\mathrm{P}(\mathrm{AETAC}-\mathrm{X})_{76}$ stabilizer, which corresponds to a $20 \%$ average increase of the number of particles at both initial solids content (see SC1-PX 76 4-E4, SC1-PX 9 4-E4 and SC5-PX 76 4-E4, SC5-PX 9 4-E4 in Table 4). As the weight fraction of the reactive stabilizer is constant at $4 \mathrm{wt}-\%$ on the basis of VCL, the number of moles of stabilizing cationic polymer chains is indeed higher for $\mathrm{PX}_{9}$ to produce more stabilizing amphiphilic polymer chains. The improvement of the colloidal stability of the PVCL-based microgels synthesized using the $\mathrm{P}($ AETAC-X) reactive stabilizers suggests a successful transfer of the PVCL growing chains to the xanthate chain-end of the $\mathrm{P}(\mathrm{AETAC}-\mathrm{X})$ to promote in-situ formation of surfaceactive amphiphilic P(AETAC)- $b$-PVCL block copolymers. In order to give some evidence of the synthesis of P(AETAC)- $b$-PVCL amphiphilic block copolymers concomitantly to the microgel growing, VCL emulsion polymerization was carried out in the absence of EGDMA crosslinker. The crude solution at low conversion was characterized by diffusion ordered spectroscopy (DOSY) NMR. This analysis pointed out the presence of P(AETAC) and PVCL homopolymers indicating that diblock copolymers are probably not synthesized at the early stage of the polymerization. However, due to the low initial weight fraction of P(AETAC-X) stabilizer with respect to VCL, the characteristic ${ }^{1} \mathrm{H}$ NMR signal of $\mathrm{P}(\mathrm{AETAC}-\mathrm{X})$ polymer is not easily detected for intermediate monomer conversions as the intensity of the PVCL proton signals rapidly predominates. To circumvent this issue, the PVCL-based microgels (SC1-PX 76 4-E4 and SC5-PX 76 4-E4 of Table 4) were centrifuged once in order to analyze the supernatants by DOSY NMR. The presence of a single diffusion coefficient in the DOSY NMR spectra of the supernatants in $\mathrm{D}_{2} \mathrm{O}$, correlated with characteristic proton NMR signals of both types of units (signal $d$ for AETAC, signal A, B, E, F, G for PVCL in Figure S.17 in Supporting 
Information), revealed the effective formation of P(AETAC)- $b$-PVCL amphiphilic block copolymers, concomitantly to the growing of PVCL crosslinked polymer.

\section{Effect of the amount of stabilizer on the colloidal features.}

In this section, the effect of the level of cationic macromolecular stabilizer (PX) on the colloidal features of the PVCL-based microgels synthesized by batch emulsion polymerization of VCL will be investigated (see Table 2 and polymer codes in the experimental part). It is noticed from the colloidal features of the microgels which are gathered in Table 4 that the amount of the reactive cationic macromolecular stabilizer influenced the final number of particles. The threshold value of $\mathrm{P}(\mathrm{AETAC}-\mathrm{X})$ is $4 \mathrm{wt}-\%$ as lower amount produced unstable dispersions of microgels. By increasing the concentration of $\mathrm{P}(\text { AETAC-X) })_{76}$ stabilizer from 4 to $8 \mathrm{wt}-\%$, the number of microgel particles remained constant for emulsion polymerization carried out at 1 wt-\% of solids content (SC1-PX 76 4-E4 and SC1-PX 76 8-E4 in Table 4). Targeting 12 wt-\% of the $\mathrm{P}(\mathrm{AETAC}-\mathrm{X})_{16}$ stabilizer induced four-fold increase of the number of particles (SC1-PX 16 4-E4 and SC1-PX 16 12-E4 in Table 4). Such trend confirms the involvement of the reactive P(AETAC-X) hydrophilic polymer to ensure the stability of the primary nuclei formed in the early stage of emulsion polymerization therefore acting on the final number of particles. The decrease of the degree of polymerization of the reactive stabilizer $\left(\mathrm{P}(\mathrm{AETAC}-\mathrm{X})_{9}\right)$ induced an increase of the final number of particles in a $20 \%$ range $(\mathrm{SC} 1-\mathrm{PX} 764-\mathrm{E} 4$ and SC1-PX 9 4-E4 in Table 4). As the weight fraction of the reactive stabilizer is kept constant at $4 \mathrm{wt}-\%$ on the basis of VCL, the number of moles of stabilizing cationic polymer chains is indeed higher for the lower degree of polymerization. The stable PVCL-based microgels synthesized by emulsion polymerization in the presence of the reactive $\mathrm{P}(\mathrm{AETAC}-\mathrm{X})$ stabilizers exhibit a thermoresponsive behavior with a volumetric shrinkage upon heating (Figure 3). 


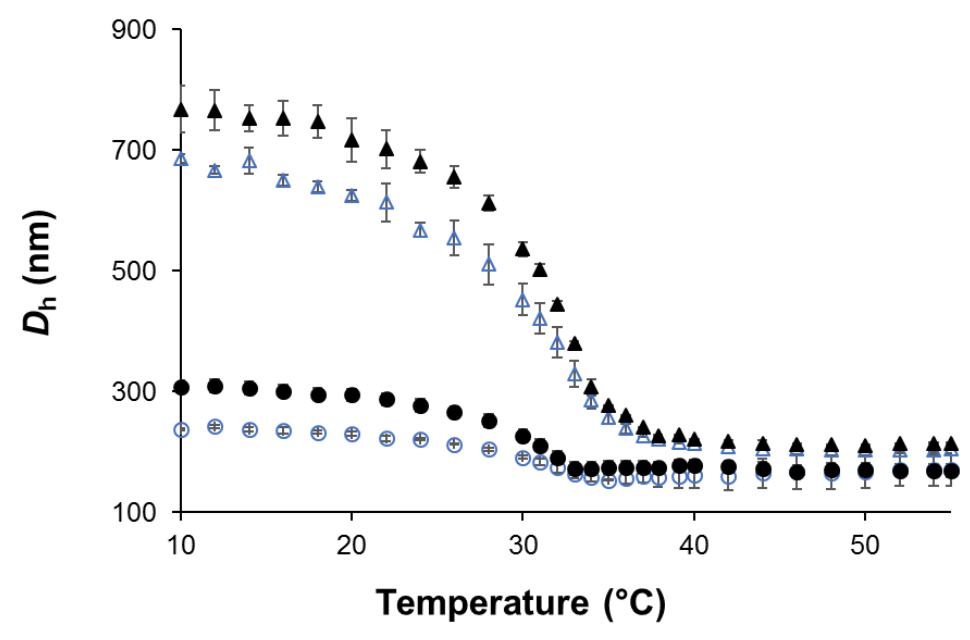

Figure 3. Final average hydrodynamic diameters as a function of the temperature for the microgels synthesized at: 1 wt- $\%$ of initial solids content and $\boldsymbol{\Delta} 5 \mathrm{wt}-\%$ of initial solids content; Full symbols: 4 wt-\% of P(AETAC-X) $)_{76}$ stabilizer based on VCL (SC1-PX 76 4-E4 and SC5-PX 76 4-E4 in Table 2), Open symbols: 8 wt-\% of P(AETAC-X) 76 stabilizer based on VCL (SC1-PX 76 8-E4 and SC5-PX 76 8-E4 in Table 2).

The impact of the initial concentration of the $\mathrm{P}(\mathrm{AETAC}-\mathrm{X})$ reactive stabilizer on the swelling behavior of the PVCL-based microgels was investigated in this part. The initial amount of $\mathrm{P}(\mathrm{AETAC}-\mathrm{X})_{76}$ stabilizer was ranged from 4 to $8 \mathrm{wt}-\%$ based on VCL for polymerization carried out in aqueous dispersed media at $1 \mathrm{wt}-\%$ of initial solids content (Table 4). The increase of the $\mathrm{P}(\mathrm{AETAC}-\mathrm{X})_{76}$ concentration slightly reduced the diameter measured at swollen state (see $D_{\mathrm{h}}$ at $10^{\circ} \mathrm{C}$ for SC1-PX 76 4-E4 and SC1-PX 76 8-E4 microgels in Table 4 and Figure 3). A similar trend was observed by increasing the amount of the P(AETAC-X) ${ }_{16}$ stabilizer with lower theoretical DP from $4 \mathrm{wt}-\%$ to $12 \mathrm{wt}-\%$ with a more pronounced decrease of the hydrodynamic diameter at both $10^{\circ} \mathrm{C}$ and $55^{\circ} \mathrm{C}$ (see Figure S.15 in Supporting Information and Table 4). It has been well-established that the introduction of ionic co-monomer into thermoresponsive microgels induces an increase of the VPTT value as the increase of the 
internal osmotic pressure of the gel through electrostatic repulsions and counter-ions mobility leads to additional swelling of the gel. ${ }^{42,67,68}$ For instance, Pich et al. ${ }^{20,21}$ showed that the introduction of 1 to 5 mol- $\%$ of vinylimidazole cationic co-monomer into PVCL-based microgels shifted the VPTT value from $35^{\circ} \mathrm{C}$ to $45^{\circ} \mathrm{C}$. The interest of the present system is to enable the increase of the fraction of cationic units (from 4 to $8 \mathrm{wt}-\%$, ie, 3 to 6 mol- $\%$ based on VCL) at the surface of the microgel while retaining a constant VPTT value close to $30^{\circ} \mathrm{C}$ (Table 4). Note that raising the content of the reactive P(AETAC-X) $)_{16}$ stabilizer up to $12 \mathrm{wt}-\%$ based on VCL induced the formation of crosslinked particles with a constant hydrodynamic diameter over the temperature range of 10 to $55^{\circ} \mathrm{C}$ (Figure S.15 in Supporting Information). The absence of volume phase transition when increasing the content of the reactive P(AETACX) stabilizer suggests that the cationic polyelectrolyte shell limits the network swelling. Indeed, some previous examples showed that the presence of a shell, consisting of either crosslinked P(NIPAAm $)^{69}$ or iron oxide nanoparticles,${ }^{70}$ restricted the core from swelling to its native volume. This result confirms the role of the reactive cationic macromolecular chain-transfer agent to act as stabilizer, hence anchoring a polymeric cationic outer shell onto the PVCL-based microgels. In order to confirm the presence of a cationic outer shell in the synthesized PVCLbased microgels, the electrophoretic mobility of the microgels synthesized using different concentrations of reactive stabilizers was measured at $25^{\circ} \mathrm{C}$, in cationic buffer solution at $\mathrm{pH} 3$ and $10 \mathrm{mM}$ of ionic strength (Table S.1, Supporting Information). For the whole series of microgels, the electrophoretic mobility values are positives, which is consistent with the presence of cationic charges. The values of the electrophoretic mobility of the PVCL-based microgels synthesized using the reactive $\mathrm{P}(\mathrm{AETAC}-\mathrm{X})$ as stabilizer are higher than the electrophoretic mobility of the counterpart PVCL microgels synthesized in the absence of stabilizer (SC5-0-E4 sample of Table 4). This corroborates the presence of the cationic macromolecular stabilizer on the outer shell of the synthesized PVCL-based microgels. For 
experiments carried out at the same level of initial solids content, the microgel electrophoretic mobility increased according to the increase of the initial amount of the reactive cationic stabilizer (see SC1-PX 76 4-E4 and SC1-PX 76 8-E4 in Table S.1). For the microgels synthesized at $1 \mathrm{wt}-\%$ of initial solids content and $4 \mathrm{wt}-\%$ of reactive stabilizer, we observed that the degree of polymerization of the reactive stabilizer (either $\mathrm{P}(\mathrm{AETAC}-\mathrm{X})_{76}$ or $\left.\mathrm{P}(\mathrm{AETAC}-\mathrm{X})_{9}\right)$, has no significant effect on the electrophoretic mobility $\left(\mathrm{SC} 1-\mathrm{PX}{ }_{76} 4-\mathrm{E} 4\right.$ and SC1-PX 9 4-E4 in Table S.1).

3. Effect of the solids content used during the synthesis of PVCL microgels on the colloidal features.

Most of the previous studies reporting the synthesis of PVCL-based microgels were performed at solids content below $5 \mathrm{wt}-\%$ to limit the occurrence of macrogelation. ${ }^{21-23,26,65,67,71,72}$ Imaz et $a{ }^{22}$ observed for instance the formation of a macroscopic gel during the emulsion polymerization of VCL carried out at $5 \mathrm{wt}-\%$ of solids content with $4 \mathrm{wt}-\%$ of sodium dodecyl sulfate as molecular surfactant, $1 \mathrm{wt}-\%$ of potassium persulfate as initiator and $4 \mathrm{wt}-\%$ of $N, N^{\prime}-$ methylenebis(acrylamide) as crosslinker. We showed in the present work that the reactive P(AETAC-X) cationic polymers are effective electro-steric stabilizers to increase the solids content of the final dispersion of thermoresponsive PVCL-based microgels while maintaining a good level of colloidal stability (absence of flocculation or coagulation). However, we observed that whatever the stabilizer content and its chain length, the hydrodynamic diameter of the swollen PVCL-based microgels measured at $10^{\circ} \mathrm{C}$ is systematically higher for the microgels synthesized at 5 wt-\% of solids content $\left(\mathrm{SC}_{-1}-\mathrm{PX}_{76} 4-\mathrm{E} 4, \mathrm{SC}_{5}-\mathrm{PX} 94-\mathrm{E} 4\right)$ in comparison to the microgels synthesized at $1 \mathrm{wt}-\%$ of solids content (SC1-PX 76 4-E4, SC1-PX 9 4-E4) (Figure 3 and Table 4). It should be mentioned a difference between the initial states of the VCL polymerization carried out in aqueous dispersed media. According to Aguirre et al. ${ }^{73}$ and Kozanoglu et al.,${ }^{74}$ the limit concentrations of solubility in water of VCL and EGDMA are 
as follows: $[\mathrm{VCL}]_{\text {limit, water }}=41 \mathrm{~g} \cdot \mathrm{L}^{-1}$ and $[\mathrm{EGDMA}]_{\text {limit, water }}=1 \mathrm{~g} \cdot \mathrm{L}^{-1} \cdot{ }^{74,73}$ Consequently, at 1 wt-\% of initial solids content, both VCL monomer and EGDMA crosslinker are soluble in the continuous aqueous phase $\left([\mathrm{VCL}]_{0}=10 \mathrm{~g} \cdot \mathrm{L}^{-1}\right.$ and $\left.[\mathrm{EGDMA}]_{0}=0.4 \mathrm{~g} \cdot \mathrm{L}^{-1}\right)$ so the polymerization follows a precipitation polymerization process as PVCL precipitates at $70{ }^{\circ} \mathrm{C}$. On the contrary, monomer droplets dispersed in the aqueous phase are observed for higher initial solids content (Figure S.16) as the concentrations of both VCL and EGDMA ([VCL $]_{0}=50$ g.L ${ }^{-1}$ and $[\text { EGDMA }]_{0}=2$ g.L $\mathrm{L}^{-1}$ for $5 \mathrm{wt}-\%$ of solids content) are above their limit concentrations of solubility in water. At 5 and 10 wt-\% of initial VCL content, the polymerization occurs via an emulsion polymerization process. Thus, the diffusion of both VCL and crosslinker across the water phase in emulsion process might induce a difference in the inner structure of the PVCL microgel. To address this point, the P(AETAC-X)-stabilized PVCL-based microgels were first analyzed by means of proton nuclear magnetic resonance transverse relaxation $\left(T_{2} \mathrm{NMR}\right)$ measurements (see experimental part and Figure S.3 and Figure S.4 in Supporting Information).

Table 6. Proton transverse relaxation times $\left(T_{2 \mathrm{~S}}\right.$ and $\left.T_{2 \mathrm{~L}}\right)$ and relative weight coefficients for the PVCL-based microgels synthesized using $4 \mathrm{wt}-\%$ of P(AETAC-X) 76 stabilizer based on VCL, at different initial solids contents.

\begin{tabular}{cccccc}
\hline Sample & $\boldsymbol{T}_{\mathbf{2 S}}$ & $\boldsymbol{C s}$ & $\boldsymbol{T}_{\mathbf{2}}$ & $\boldsymbol{C}_{\mathbf{L}}$ & $\frac{\mathbf{C L D}^{\text {core }}}{\mathbf{C L D}^{\text {shell }}}$ \\
& $m s$ & & $m s$ & & 1.9 \\
\hline SC1-PX $_{76} 4-\mathrm{E} 4$ & 0.42 & 0.26 & 1.45 & 0.77 & 2.2 \\
$\mathrm{SC5} \mathrm{PX}_{76} 4-\mathrm{E} 4$ & 0.69 & 0.32 & 3.18 & 0.69 & \\
\hline
\end{tabular}

The results of proton nuclear magnetic resonance transverse relaxation fitted by two different transverse relaxation times (Table 6) confirmed the core-shell morphology suggested by the polymerization kinetics reported in Figure S.12 (Supporting Information). It was deduced from the values of $\mathrm{CLD}^{\text {core }} / \mathrm{CLD}^{\text {shell }}$ ratios of the PVCL-based microgels that the core is twice more 
crosslinked than the shell. The content of PVCL chains located in the shell $\left(C_{\mathrm{L}}\right)$ is higher than in the core $(C s)$ for microgels synthesized at both solids contents $(\mathrm{SC} 1-\mathrm{PX} 76$ 4-E4 and SC5$\mathrm{PX}_{76}$ 4-E4 microgels in Table 6). The EGDMA crosslinker provided a more homogeneous microstructure in comparison with $N, N^{\prime}$-methylenebisacrylamide (MBA) crosslinker as the ratios of the average cross-linking density between the core and shell are lower with EGDMA. Indeed values of $\mathrm{CLD}^{\text {core }} / \mathrm{CLD}^{\text {shell }}$ ratios of 3.0 - 3.4 were previously reported for PVCL-based microgels crosslinked with 4 wt- $\%$ of MBA, ${ }^{25,26}$ while $\mathrm{CLD}^{\text {core }} / \mathrm{CLD}^{\text {shell }}$ ratios of $1.9-2.2$ were observed in the present work (Table 6). Regarding the comparison of the microgels synthesized by polymerization in aqueous dispersed media at either 1 or $5 \mathrm{wt}-\%$ of solids content, it can be noticed that the values of $\mathrm{CLD}^{\text {core }} / \mathrm{CLD}^{\text {shell }}$ ratios are very close in a range of $10 \%$ (Table 6), which cannot justify the discrepancy between the values of the swelling ratios reported in Table 7.

Small angle neutron scattering (SANS) is a technique used for investigating the inner structure of microgels. ${ }^{75-77}$ In the present work, SANS measurements were undertaken on the cationic PVCL microgels in order to probe the effect of both the temperature and the initial solids content on their inner structure.

a)

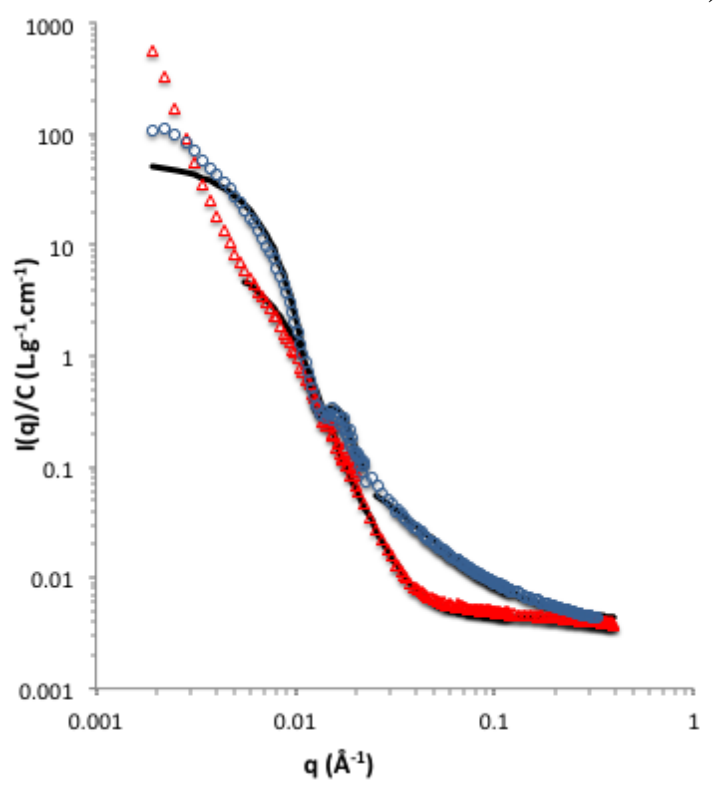

b)

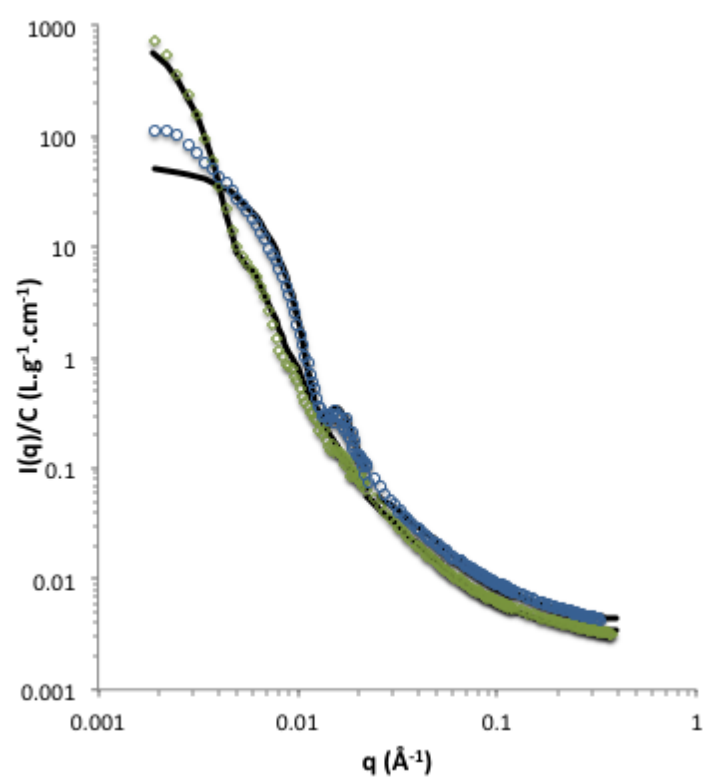


Figure 4. Small angle neutron scattering (SANS) curves of PVCL microgels dispersed in $\mathrm{D}_{2} \mathrm{O}$ at 20 g.L $\mathrm{L}^{-1}$ : a) Influence of the measurement temperature on the SC1-PX 76 4-E4 cationic PVCL microgel (empty red triangle for $\mathrm{T}=50^{\circ} \mathrm{C}$ and empty blue circle for $\mathrm{T}=10{ }^{\circ} \mathrm{C}$ ); b) Influence of the initial solids content used for PVCL microgel synthesis (1 or $5 \mathrm{wt}-\%$ ) on SANS measured at $\mathrm{T}=10{ }^{\circ} \mathrm{C}: \mathrm{SC} 1-\mathrm{PX}_{76} 4-\mathrm{E} 4$ (empty blue circle) and $\mathrm{SC}-\mathrm{PX}_{76} 4-\mathrm{E} 4$ (empty green diamond). Black lines correspond to the fits of experimental data (see experimental part).

Typical SANS curves of SC1-PX 76 4-E4 cationic PVCL microgel were measured at different temperatures, below and above the VPTT, in order to probe the temperature-induced transitions (Figure 4a). The change of the scattering curves with temperature confirmed the morphological transition of the thermo-responsive PVCL microgels. Indeed, at low temperature $\left(\mathrm{T}=10^{\circ} \mathrm{C}\right)$, a plateau is observed at low $q$ range followed by an oscillation characteristic of monodisperse spheres while at higher temperature $\left(\mathrm{T}=50^{\circ} \mathrm{C}\right)$ the oscillation disappears being replaced by a shoulder of the curve shifted toward higher $q$ values. The size of the scattering objects thus decreased and became more polydisperse. This corresponds to a collapse of the dense part of microgels at higher temperature. At the collapsed state $\left(\mathrm{T}=50^{\circ} \mathrm{C}\right.$ in Figure 4a), the increase of the scattering intensity at low $q$-range varying according to a Porod's law (in $q^{-4}$ ) revealed the presence of dense and large heterogeneities of the network as already observed for other microgels. ${ }^{75-77}$ SANS data recorded at $10^{\circ} \mathrm{C}$ were fitted using two simple models: the polydisperse sphere model at low $q$-range describing the dense part of microgels (Equation 5) and the Lorentz model in the high $q$-range to characterize the mesh size of the microgel network (Equation 6). Though more complex models were reported in the literature to describe the structure of microgels, ${ }^{75-77}$ the both models applied in the present work were sufficient to describe the parameters of interest like the mean diameter ( $\left.D_{\text {SANS }}\right)$, the polydispersity $(\sigma)$ and the mesh size $(\xi)$ (see Table 7). 
Table 7. Structural properties of the network of PVCL microgels. ${ }^{a}$

\begin{tabular}{|c|c|c|c|c|}
\hline Sample & $\Phi$ & $\begin{array}{c}\xi \\
\mathrm{T}=10^{\circ} \mathrm{C}\end{array}$ & $\begin{array}{c}D_{\text {SANS }} \\
\mathrm{T}=10^{\circ} \mathrm{C}\end{array}$ & $\begin{array}{c}\sigma \\
\mathrm{T}=10^{\circ} \mathrm{C}\end{array}$ \\
\hline & & $n m$ & $n m$ & \\
\hline SC1-PX 76 4-E4 & 6 & 6 & 66 & 0.13 \\
\hline $\mathrm{SC}-\mathrm{PX}_{76} 4-\mathrm{E} 4$ & 46 & 15 & 162 & 0.20 \\
\hline SC1-PX $94-E 4$ & 9 & 5 & 92 & 0.20 \\
\hline $\mathrm{SC}_{5-\mathrm{PX}} 9$ 4-E4 & 33 & 8 & 144 & 0.20 \\
\hline
\end{tabular}

${ }^{a}$ Swelling ratio: $\Phi=\left(D_{\mathrm{h}, 10^{\circ} \mathrm{C}} / D_{\mathrm{h}, 55^{\circ} \mathrm{C}}\right)^{3}$ (see Table 4 for $D_{\mathrm{h}}$ values), $\xi$ is the mesh size of the network, and $\sigma$ is the polydispersity of the sphere.

The SANS data confirmed the trend observed by DLS in the sense that the increase of the initial solids content induced a shift of the SANS curves towards lower $q$ values (Figure 4b), which is characteristic of an increase of the mean diameter of the sphere (see SC1 versus SC5 samples in Table 7). It can be noticed that the average diameters of PVCL microgels measured by SANS (Table 7) are systematically lower than the hydrodynamic diameters measured by DLS at $10^{\circ} \mathrm{C}$ (Table 4), which is due to the difference in $q$-range. ${ }^{78}$ Moreover, SANS data highlighted an impact of the initial solids content used for the microgel synthesis on the mesh size $\xi$ of the network. Thus, the increase of the swelling ratio $\left(\Phi=\left(D_{\mathrm{h}, 10^{\circ} \mathrm{C}} / D_{\mathrm{h}, 55^{\circ} \mathrm{C}}\right)^{3}\right)$ observed between the PVCL microgels synthesized at 1 or $5 \mathrm{wt}-\%$ of solids content can be correlated with the increase of the mesh size $\xi$ of the polymer network (Table 7). The ratios of the mesh sizes for SC1 and SC5 series, which are characteristic of the mesh volume ratios $\left(\left(\xi_{\mathrm{SC} 5-\mathrm{PX} 94-\mathrm{E} 4} / \boldsymbol{\xi}_{\mathrm{SC} 1-\mathrm{PX} 94-\mathrm{E} 4}\right)^{3}=4.0\right.$, $\left.\left(\xi_{\mathrm{SC} 5-\mathrm{PX} 76} 4-\mathrm{E} 4 / \xi_{\mathrm{SC} 1-\mathrm{PX} 76} 4-\mathrm{E} 4\right)^{3}=15.0\right)$, increased according to the increase of the macroscopic swelling ratios calculated from the hydrodynamic diameters $\left(\Phi_{\mathrm{SC} 5-\mathrm{PX} 9}^{4-\mathrm{E} 4} / \Phi_{\mathrm{SC} 1-\mathrm{PX} 94-\mathrm{E} 4}=3.7\right.$, 


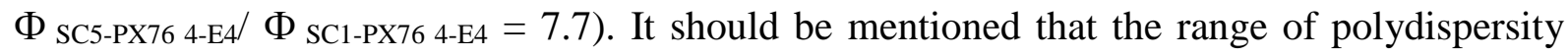
values $(\sigma<0.2)$ is low compared to values genrally reported for gels, which confirms that the cationic PVCL microgels synthesized in the present work are peculiarly well-defined at at 10 ${ }^{\circ} \mathrm{C}$.

\section{CONCLUSIONS}

In this work, the efficiency of the reactive cationic macromolecular chain-transfer agents synthesized by RAFT/MADIX polymerization to act as stabilizers for the synthesis of cationic thermoresponsive poly( $N$-vinylcaprolactam)-based microgels by a heterogeneous polymerization process in aqueous media was thoroughly investigated. Stable and monodisperse PVCL-based microgels were prepared using reactive $\mathrm{P}(\mathrm{AETAC}-\mathrm{X})$ as macromolecular stabilizers. The improvement of the stabilization efficiency by using the xanthate-functionalized P(AETAC-X) polymers was highlighted by comparing the colloidal features of the PVCL microgels with those synthesized by using the non-reactive cationic polymeric or molecular stabilizers. For the entire range of initial solids contents ( $\tau=1$ to $10 \mathrm{wt}-$ $\%)$, stable PVCL-based microgels were synthesized in the presence of the reactive xanthate functionalized $\mathrm{P}(\mathrm{AETAC}-\mathrm{X})_{76}$ stabilizer while particle flocculation or coagulation were observed during emulsion polymerization using the other stabilizers. These results highlighted the key role played by the reactive xanthate chain-end in the colloidal stabilization of microgels during the polymerization process. The involvement of this reactive chain-end in the microgel growing step was also suggested by the effect of the fraction of $\mathrm{P}(\mathrm{AETAC}-\mathrm{X})$ on the final number of particles, on the microgel hydrodynamic diameters at swollen state and on the value of microgel electrophoretic mobility. Taking advantage of this living chain-end, stable thermoresponsive monodisperse PVCL-based microgels with robust colloidal features were synthesized for the first time up to a $10 \mathrm{wt}-\%$ of initial solids content. 
The synthesized microgels exhibited a thermoresponsive behavior with a volumetric shrinkage upon heating. The volume phase transition temperature (VPTT) ranged between $28{ }^{\circ} \mathrm{C}$ and $30^{\circ} \mathrm{C}$ for the microgels synthesized using 4 and 8 wt- $\%$ of P(AETAC-X) based on VCL. The increase of the microgel electrophoretic mobility when increasing the amount of P(AETAC-X) stabilizer highlighted the interest of using a reactive macromolecular stabilizer to design PVCLbased thermoresponsive microgels with functional cationic macromolecular shell. The swelling behavior of the microgel particles can be tuned by the amount of P(AETAC-X) stabilizer and the initial solids content. The internal structure of microgels was probed by SANS measurements and proton NMR transverse relaxation decay. These characterizations described monodisperse spheres with a core-shell morphology. The temperature-induced swelling-tocollapse transition was associated with a decrease of the network mesh size that was also impacted by the initial solids content chosen for PVCL microgel synthesis. The swelling ratio of the microgels can be accordingly tuned by the initial solids content.

\section{ACKNOWLEDGEMENTS}

The French ministry of research, the University of Pau \& Pays Adour (ED Sciences 211) and the University of the Basque Country UPV/EHU are acknowledged for funding L.E.'s PhD work performed under a joint doctorate program. The Equipex Xyloforest program (ANR-10EQPX-16 XYLOFOREST) is acknowledged for NMR probe funding. The authors are grateful to A. Khoukh for his support with DOSY NMR technique, P. Beaunier for TEM imaging and A. Aguirre and M. Aguirre, for their participation in the A4F analyses. This work benefited from the use of the SasView application, originally developed under NSF award DMR0520547.

Supporting Information. Proton NMR spectra, DOSY NMR scpectra, proton NMR transverse relaxation decay, Hydrodynamic diameters versus temperature curves: comparison of dialyzed 
and non-dialyzed samples, monomer and logarithmic monomer conversion versus time, A-4F fractograms and SEC chromatograms of $\mathrm{P}(\mathrm{AETAC}-\mathrm{X})$, angular dependence of hydrodynamic diameter of $\mathrm{P}(\mathrm{AETAC}-\mathrm{X}) 14$ polymer in different aqueous solutions, chemical structures of the different stabilizers, pictures of initial state, flocculation and coagulum, table with microgels electrophoretic mobility values.

\section{REFERENCES}

(1) Gil, E.; Hudson, S. Stimuli-reponsive polymers and their bioconjugates. Prog. Polym. Sci. 2004, 29, 1173-1222.

(2) Stuart, M. A.; Huck, W. T.; Genzer, J.; Muller, M.; Ober, C.; Stamm, M.; Sukhorukov, G. B.; Szleifer, I.; Tsukruk, V. V.; Urban, M.; Winnik, F.; Zauscher, S.; Luzinov, I.; Minko, S. Emerging applications of stimuli-responsive polymer materials. Nature materials 2010, 9, 10113.

(3) Hoffman, A. S. Stimuli-responsive polymers: biomedical applications and challenges for clinical translation. Advanced drug delivery reviews 2013, 65, 10-6.

(4) de Las Heras Alarcon, C.; Pennadam, S.; Alexander, C. Stimuli responsive polymers for biomedical applications. Chemical Society reviews 2005, 34, 276-85.

(5) Schmaljohann, D. Thermo- and $\mathrm{pH}-$ responsive polymers in drug delivery. Advanced drug delivery reviews 2006, 58, 1655-70.

(6) Saunders, B. R.; Laajam, N.; Daly, E.; Teow, S.; Hu, X.; Stepto, R. Microgels: From responsive polymer colloids to biomaterials. Advances in colloid and interface science $\mathbf{2 0 0 9}$, $147-148,251-62$.

(7) Liu, Guangyao; An, Zesheng. Frontiers in the design and synthesis of advanced nanogels for nanomedicine. Polym. Chem. 2014, 5, 1559-1565. 
(8) Motornov, Mikhail; Roiter, Yuri; Tokarev, Ihor; Minko, Sergiy. Stimuli-responsive nanoparticles, nanogels and capsules for integrated multifunctional intelligent systems. Prog. Polym. Sci. 2010, 35, 174-211.

(9) Oh, Jung Kwon; Drumright, Ray; Siegwart, Daniel J.; Matyjaszewski, Krzysztof. The development of microgels/nanogels for drug delivery applications. Prog. Polym. Sci. 2008, 33, 448-477.

(10) Smeets, Niels M. B.; Hoare, Todd. Designing responsive microgels for drug delivery applications. J. Polym. Sci., Part A: Polym. Chem. 2013, 51, 3027-3043.

(11) Lyon, L. A.; Meng, Z.; Singh, N.; Sorrell, C. D.; St John, A. Thermoresponsive microgel-based materials. Chemical Society reviews 2009, 38, 865-74.

(12) Kawaguchi, Haruma. Thermoresponsive microhydrogels: preparation, properties and applications. Polym. Int. 2014, 63, 925-932.

(13) Raemdonck, Koen; Demeester, Joseph; De Smedt, Stefaan. Advanced nanogel engineering for drug delivery. Soft Matter 2009, 5, 707-715.

(14) Ramos, J.; Forcada, J.; Hidalgo-Alvarez, R. Cationic polymer nanoparticles and nanogels: from synthesis to biotechnological applications. Chem. Rev. 2014, 114, 367-428.

(15) Hertle, Yvonne; Hellweg, Thomas. Thermoresponsive copolymer microgels. Journal of Materials Chemistry B 2013, 1, 5874.

(16) Ramos, Jose; Imaz, Ainara; Forcada, Jacqueline. Temperature-sensitive nanogels: poly(N-vinylcaprolactam) versus poly(N-isopropylacrylamide). Polym. Chem. 2012, 3, 852856.

(17) Liu, J.; Debuigne, A.; Detrembleur, C.; Jerome, C. Poly(N-vinylcaprolactam): a thermoresponsive macromolecule with promising future in biomedical field. Advanced healthcare materials 2014, 3, 1941-68. 
(18) Vihola, Henna; Laukkanen, Antti; Hirvonen, Jouni; Tenhu, Heikki. Binding and release of drugs into and from thermosensitive poly(N-vinyl caprolactam) nanoparticles. European Journal of Pharmaceutical Sciences 2002, 16, 69-74.

(19) Laukkanen, A.; Wiedmer, S. K.; Varjo, S.; Riekkola, M. L.; Tenhu, H. Stability and thermosensitive properties of various poly ( $\mathrm{N}$-vinylcaprolactam) microgels. Colloid \& Polymer Science 2002, 280, 65-70.

(20) Pich, Andrij; Tessier, Anne; Boyko, Volodymyr; Lu, Yan; Adler, Hans-Juergen P. Synthesis and Characterization of Poly(vinylcaprolactam)-Based Microgels Exhibiting Temperature and pH-Sensitive Properties. Macromolecules 2006, 39, 7701-7707.

(21) Schachschal, Susann; Balaceanu, Andreea; Melian, Claudiu; Demco, Dan E.; Eckert, Thomas; Richtering, Walter; Pich, Andrij. Polyampholyte Microgels with Anionic Core and Cationic Shell. Macromolecules 2010, 43, 4331-4339.

(22) Imaz, Ainara; Forcada, Jacqueline. N-vinylcaprolactam-based microgels: Synthesis and characterization. J. Polym. Sci., Part A: Polym. Chem. 2008, 46, 2510-2524.

(23) Imaz, Ainara; Forcada, Jacqueline. N-vinylcaprolactam-based microgels: Effect of the concentration and type of cross-linker. J. Polym. Sci., Part A: Polym. Chem. 2008, 46, 27662775.

(24) Imaz, Ainara; Forcada, Jacqueline. Optimized buffered polymerizations to produce Nvinylcaprolactam-based microgels. European Polymer Journal 2009, 45, 3164-3175.

(25) Balaceanu, Andreea; Demco, Dan E.; Möller, Martin; Pich, Andrij. Microgel Heterogeneous Morphology Reflected in Temperature-Induced Volume Transition and1H High-Resolution Transverse Relaxation NMR. The Case of Poly(N-vinylcaprolactam) Microgel. Macromolecules 2011, 44, 2161-2169.

(26) Aguirre, Garbiñe; Ramos, Jose; Forcada, Jacqueline. Synthesis of new enzymatically degradable thermo-responsive nanogels. Soft Matter 2013, 9, 261-270. 
(27) Wang, Y.; Nie, J.; Chang, B.; Sun, Y.; Yang, W. Poly(vinylcaprolactam)-based biodegradable multiresponsive microgels for drug delivery. Biomacromolecules 2013, 14, 3034-46.

(28) Wang, Yang; Zheng, Jin; Tian, Yefei; Yang, Wuli. Acid degradable poly(vinylcaprolactam)-based nanogels with ketal linkages for drug delivery. J. Mater. Chem. B 2015, 3, 5824-5832.

(29) Melle, Andrea; Balaceanu, Andreea; Kather, Michael; Wu, Yaodong; Gau, Elisabeth; Sun, Wenjie; Huang, Xiaobin; Shi, Xiangyang; Karperien, Marcel; Pich, Andrij. Stimuliresponsive poly(N-vinylcaprolactam-co-2-methoxyethyl acrylate) core-shell microgels: facile synthesis, modulation of surface properties and controlled internalisation into cells. Journal of Materials Chemistry B 2016, 4, 5127-5137.

(30) Phua, D. I.; Herman, K.; Balaceanu, A.; Zakrevski, J.; Pich, A. Reversible Size Modulation of Aqueous Microgels via Orthogonal or Combined Application of Thermo- and Phototriggers. Langmuir 2016, 32, 3867-3879.

(31) Schmitz, D.; Pich, A. Responsive microgels with supramolecular crosslinks: synthesis and triggered degradation in aqueous medium. Polym. Chem. 2016, 7, 5687-5697.

(32) Aguirre, Garbine; Villar-Alvarez, Eva; Gonzalez, Adrian; Ramos, Jose; Taboada, Pablo; Forcada, Jacqueline. Biocompatible Stimuli-Responsive Nanogels for Controlled Antitumor Drug Delivery. Journal of Polymer Science Part a-Polymer Chemistry 2016, 54, 1694-1705.

(33) Aguirre, Garbine; Ramos, Jose; Forcada, Jacqueline. Advanced design of t and pH dualresponsive PDEAEMA-PVCL core-shell nanogels for siRNA delivery. Journal of Polymer Science Part a-Polymer Chemistry 2016, 54, 3203-3217.

(34) Sun, Wenjie; Thies, Sabrina; Zhang, Jiulong; Peng, Chen; Tang, Guangyu; Shen, Mingwu; Pich, Andrij; Shi, Xiangyang. Gadolinium-Loaded Poly(N-vinylcaprolactam) 
Nanogels: Synthesis, Characterization, and Application for Enhanced Tumor MR Imaging. Acs Applied Materials \& Interfaces 2017, 9, 3411-3418.

(35) Carlsson, Linn; Fall, Andreas; Chaduc, Isabelle; Wagberg, Lars; Charleux, Bernadette; Malmstrorn, Eva; D'Agosto, Franck; Lansalot, Muriel; Carlmark, Anna. Modification of cellulose model surfaces by cationic polymer latexes prepared by RAFT-mediated surfactantfree emulsion polymerization. Polym. Chem. 2014, 5, 6076-6086.

(36) Samal, Sangram Keshari; Dash, Mamoni; Van Vlierberghe, Sandra; Kaplan, David L.; Chiellini, Emo; van Blitterswijk, Clemens; Moroni, Lorenzo; Dubruel, Peter. Cationic polymers and their therapeutic potential. Chem. Soc. Rev. 2012, 41, 7147-7194.

(37) Berger, Sebastian; Singh, Rekha; Sudha, Janardhanannair D.; Adler, Hans-Juergen; Pich, Andrij. Microgel/clay nanohybrids as responsive scavenger systems. Polymer 2010, 51, 3829-3835.

(38) Wu, D. Q.; Chu, C. C.; Chen, F. A. Cationic poly(VCL-AETA) hydrogels and ovalbumin (OVA) release in vitro. Journal of materials science. Materials in medicine $\mathbf{2 0 0 8 ,}$ $19,3593-601$.

(39) Demirel, G. B.; von Klitzing, R. A new multiresponsive drug delivery system using smart nanogels. Chemphyschem 2013, 14, 2833-40.

(40) Bhattacharya, S.; Eckert, F.; Boyko, V.; Pich, A. Temperature-, pH-, and magneticfield-sensitive hybrid microgels. Small 2007, 3, 650-7.

(41) Hu, X.; Tong, Z.; Lyon, L. A. Synthesis and Physicochemical Properties of Cationic Microgels Based on Poly(N-isopropylmethacrylamide). Colloid Polym Sci 2010, 289, 333-339. (42) Hoare, T.; Pelton, R. Functionalized microgel swelling: comparing theory and experiment. The journal of physical chemistry. B 2007, 111, 11895-906.

(43) An, Z.; Shi, Q.; Tang, W.; Tsung, C. K.; Hawker, C. J.; Stucky, G. D. Facile RAFT precipitation polymerization for the microwave-assisted synthesis of well-defined, double 
hydrophilic block copolymers and nanostructured hydrogels. Journal of the American Chemical Society 2007, 129, 14493-9.

(44) Rieger, Jutta; Grazon, Chloé; Charleux, Bernadette; Alaimo, David; Jérôme, Christine. Pegylated thermally responsive block copolymer micelles and nanogels viain situRAFT aqueous dispersion polymerization. J. Polym. Sci., Part A: Polym. Chem. 2009, 47, 2373-2390. (45) Grazon, Chloé; Rieger, Jutta; Sanson, Nicolas; Charleux, Bernadette. Study of poly $(\mathrm{N}, \mathrm{N}$-diethylacrylamide) nanogel formation by aqueous dispersion polymerization of $\mathrm{N}, \mathrm{N}-$ diethylacrylamide in the presence of poly(ethylene oxide)-b-poly(N,N-dimethylacrylamide) amphiphilic macromolecular RAFT agents. Soft Matter 2011, 7, 3482.

(46) Delaittre, Guillaume; Save, Maud; Charleux, Bernadette. Nitroxide-Mediated Aqueous Dispersion Polymerization: From Water-Soluble Macroalkoxyamine to Thermosensitive Nanogels. Macromol. Rapid Commun. 2007, 28, 1528-1533.

(47) Liu, Guangyao; Qiu, Qian; Shen, Wenqing; An, Zesheng. Aqueous Dispersion Polymerization of 2-Methoxyethyl Acrylate for the Synthesis of Biocompatible Nanoparticles Using a Hydrophilic RAFT Polymer and a Redox Initiator. Macromolecules 2011, 44, 52375245.

(48) Liu, Guangyao; Qiu, Qian; An, Zesheng. Development of thermosensitive copolymers of poly(2-methoxyethyl acrylate-co-poly(ethylene glycol) methyl ether acrylate) and their nanogels synthesized by RAFT dispersion polymerization in water. Polym. Chem. 2012, 3, 504513.

(49) Bhuchar, N.; Sunasee, R.; Ishihara, K.; Thundat, T.; Narain, R. Degradable thermoresponsive nanogels for protein encapsulation and controlled release. Bioconjugate chemistry 2012, 23, 75-83. 
(50) Ahmed, Marya; Wattanaarsakit, Phanphen; Narain, Ravin. Cationic glyco-nanogels for epidermal growth factor receptor (EGFR) specific siRNA delivery in ovarian cancer cells. Polym. Chem. 2013, 4, 3829.

(51) Kotsuchibashi, Yohei; Narain, Ravin. Dual-temperature and $\mathrm{pH}$ responsive (ethylene glycol)-based nanogels via structural design. Polym. Chem. 2014, 5, 3061.

(52) Figg, C. A.; Simula, A.; Gebre, K. A.; Tucker, B. S.; Haddleton, D. M.; Sumerlin, B. S. Polymerization-induced thermal self-assembly (PITSA). Chem. Sci. 2015, 6, 1230-1236.

(53) Charleux, Bernadette; Delaittre, Guillaume; Rieger, Jutta; D'Agosto, Franck. Polymerization-Induced Self-Assembly: From Soluble Macromolecules to Block Copolymer Nano-Objects in One Step. Macromolecules 2012, 45, 6753-6765.

(54) Warren, N. J.; Armes, S. P. Polymerization-induced self-assembly of block copolymer nano-objects via RAFT aqueous dispersion polymerization. J. Am. Chem. Soc. 2014, 136, 10174-85.

(55) Canning, S. L.; Smith, G. N.; Armes, S. P. A Critical Appraisal of RAFT-Mediated Polymerization-Induced Self-Assembly. Macromolecules 2016, 49, 1985-2001.

(56) Delaittre, Guillaume; Save, Maud; Gaborieau, Marianne; Castignolles, Patrice; Rieger, Jutta; Charleux, Bernadette. Synthesis by nitroxide-mediated aqueous dispersion polymerization, characterization, and physical core-crosslinking of $\mathrm{pH}$ - and thermoresponsive dynamic diblock copolymer micelles. Polym. Chem. 2012, 3, 1526.

(57) Etchenausia, Laura; Khoukh, Abdel; Lejeune, Elise Deniau; Save, Maud. RAFT/MADIX emulsion copolymerization of vinyl acetate and N-vinylcaprolactam: towards waterborne physically crosslinked thermoresponsive particles. Polym. Chem. 2017, 8, 22442256.

(58) Perrier, Sébastien; Takolpuckdee, Pittaya; Mars, Craig A. Reversible Addition-Fragmentation Chain Transfer Polymerization: End Group Modification for 
Functionalized Polymers and Chain Transfer Agent Recovery. Macromolecules 2005, 38, 2033-2036.

(59) Pikabea, Aintzane; Aguirre, Garbiñe; Miranda, Jose I.; Ramos, Jose; Forcada, Jacqueline. Understanding of nanogels swelling behavior through a deep insight into their morphology. J. Polym. Sci., Part A: Polym. Chem. 2015, 53, 2017-2025.

(60) Ilavský, M.; Mamytbekov, G.; Sedláková, Z.; Hanyková, L.; Dušek, K. Phase transition in swollen gels 29. Temperature dependences of swelling and mechanical behaviour of poly(Nvinylcaprolactam-co-1-vinyl-2-pyrrolidone) gels in water. Polymer Bulletin 2001, 46, 99-106.

(61) Brulet, A.; Lairez, D.; Lapp, A.; Cotton, J. P. Improvement of data treatment in smallangle neutron scattering. J. Appl. Crystallogr. 2007, 40, 165-177.

(62) Guinier, A.; Fournet, G., In Small-Angle Scattering of X-Rays, John Wiley and Sons, New York: 1955.

(63) Brandrup, J.; Immergut, E. H.; Grulke, E. A., Polymer Handbook, 4th Edition. John Wiley \& Sons: 2003; p 2336.

(64) Forster, S.; Schmidt, M.; Antonietti, M. Static and dynamic light-scattering by aqueous polyelectrolyte solutions - effect of molecular-weight, charge-density and added salt. Polymer 1990, 31, 781-792.

(65) Imaz, Ainara; Forcada, Jacqueline. New Biocompatible Microgels. Macromolecular Symposia 2009, 281, 85-88.

(66) von Nessen, Katja; Karg, Matthias; Hellweg, Thomas. Thermoresponsive poly-(Nisopropylmethacrylamide) microgels: Tailoring particle size by interfacial tension control. Polymer 2013, 54, 5499-5510.

(67) Boularas, M.; Gombart, E.; Tranchant, J. F.; Billon, L.; Save, M. Design of smart oligo(ethylene glycol)-based biocompatible hybrid microgels loaded with magnetic nanoparticles. Macromol. Rapid Commun. 2015, 36, 79-83. 
(68) Rzaev, Zakir M. O.; Dinçer, Sevil; Pişkin, Erhan. Functional copolymers of Nisopropylacrylamide for bioengineering applications. Prog. Polym. Sci. 2007, 32, 534-595.

(69) Jones, Clinton D.; Lyon, L. Andrew. Shell-Restricted Swelling and Core Compression in Poly(N-isopropylacrylamide) Core-Shell Microgels. Macromolecules 2003, 36, 1988-1993. (70) Rubio-Retama, Jorge; Zafeiropoulos, Nikolaos E.; Serafinelli, Caterina; Rojas-Reyna, Rosana; Voit, Brigitte; Lopez Cabarcos, E.; Stamm, Manfred. Synthesis and Characterization of Thermosensitive PNIPAM Microgels Covered with Superparamagnetic $\gamma$-Fe2O3 Nanoparticles. Langmuir 2007, 23, 10280-10285.

(71) Boularas, Mohamed; Deniau-Lejeune, Elise; Alard, Valérie; Tranchant, Jean-François; Billon, Laurent; Save, Maud. Dual stimuli-responsive oligo(ethylene glycol)-based microgels: insight into the role of internal structure in volume phase transitions and loading of magnetic nanoparticles to design stable thermoresponsive hybrid microgels. Polym. Chem. 2016, 7, 350363.

(72) Boyko, Volodymyr; Richter, Sven; Pich, Andrij; Arndt, Karl-Friedrich. Poly( N vinylcaprolactam) microgels. Polymeric stabilization with poly(vinyl alcohol). Colloid \& Polymer Science 2003, 282, 127-132.

(73) Aguirre, Garbiñe; Ramos, Jose; Heuts, Johan P. A.; Forcada, Jacqueline. Biocompatible and thermo-responsive nanocapsule synthesis through vesicle templating. Polym. Chem. 2014, 5,4569 .

(74) Kozanoğlu, Selin; Özdemir, Tonguç; Usanmaz, Ali. Polymerization of NVinylcaprolactam and Characterization of Poly(N-Vinylcaprolactam). Journal of Macromolecular Science, Part A 2011, 48, 467-477.

(75) Ghugare, S. V.; Chiessi, E.; Fink, R.; Gerelli, Y.; Scotti, A.; Deriu, A.; Carrot, G.; Paradossi, G. Structural Investigation on Thermoresponsive PVA/Poly(methacrylate-co-N- 
isopropylacrylamide) Microgels across the Volume Phase Transition. Macromolecules 2011, $44,4470-4478$.

(76) Maccarrone, Simona; Scherzinger, Christine; Holderer, Olaf; Lindner, Peter; Sharp, Melissa; Richtering, Walter; Richter, Dieter. Cononsolvency Effects on the Structure and Dynamics of Microgels. Macromolecules 2014, 47, 5982-5988.

(77) Schneider, Florian; Balaceanu, Andreea; Feoktystov, Artem; Pipich, Vitaliy; Wu, Yaodong; Allgaier, Juergen; Pyckhout-Hintzen, Wim; Pich, Andrij; Schneider, Gerald J. Monitoring the Internal Structure of Poly(N-vinylcaprolactam) Microgels with Variable CrossLink Concentration. Langmuir 2014, 30, 15317-15326.

(78) Lindner, P.; Zemb, T., In Neutrons, X-rays and Light: Scattering Methods Applied to Soft Condensed Matter, Elsevier-North Holland Delta Series: Amsterdam: 2002. 


$$
y=-2
$$

